\title{
Computation of Tangent, Euler, and Bernoulli Numbers*
}

\section{By Donald E. Knuth and Thomas J. Buckholtz}

Abstract. Some elementary methods are described which may be used to calculate tangent numbers, Euler numbers, and Bernoulli numbers much more easily and rapidly on electronic computers than the traditional recurrence relations which have been used for over a century. These methods have been used to prepare an accompanying table which extends the existing tables of these numbers. Some theorems about the periodicity of the tangent numbers, which were suggested by the tables, are also proved.

1. Introduction. The tangent numbers $T_{n}$, Euler numbers $E_{n}$, and Bernoulli numbers $B_{n}$, are defined to be the coefficients in the following power series:

$$
\begin{aligned}
\tan z & =T_{0} / 0 !+T_{1} z / 1 !+T_{2} z^{2} / 2 !+\cdots=\sum_{n \geqq 0} T_{n} z^{n} / n !, \\
\sec z & =E_{0} / 0 !+E_{1} z / 1 !+E_{2} z^{2} / 2 !+\cdots=\sum_{n \geqq 0} E_{n} z^{n} / n !, \\
z /\left(e^{z}-1\right) & =B_{0} / 0 !+B_{1} z / 1 !+B_{2} z^{2} / 2 !+\cdots=\sum_{n \geqq 0} B_{n} z^{n} / n ! .
\end{aligned}
$$

Much of the older mathematical literature uses a slightly different notation for these numbers, to take account of the zero coefficients. Thus we find many papers where $\tan z$ is written $T_{1} z+T_{2} z^{3} / 3 !+T_{3} z^{5} / 5 !+\cdots$, sec $z$ is written $E_{0}+E_{1} z^{2} / 2 !+E_{2} z^{4} / 4 !+\cdots$, and $z /\left(e^{z}-1\right)$ is written $1-z / 2+B_{1} z^{2} / 2 !-B_{2} z^{4} / 4$ ! $+B_{3} z^{6} / 6$ ! … Some other authors have used essentially the notation defined above but with different signs; in particular our $E_{2 n}$ is often accompanied by the $\operatorname{sign}(-1)^{n}$.

In Section 2 we present simple methods for computing $T_{n}, E_{n}$, and $B_{n}$ which are readily adapted to electronic computers, and in Section 3 more details of the computer program are explained. A table of $T_{n}$ and $E_{n}$ for $n \leqq 120$, and $B_{n}$ for $n \leqq 250$, is appended to this paper, thereby extending the hitherto published values of $T_{n}$ for $n \leqq 60[6], E_{n}$ for $n \leqq 100[2,3]$, and $B_{n}$ for $n \leqq 220[7,4]$.

Using the methods of this paper it is not difficult to extend the tables much further, and the authors have submitted a copy of the values of $T_{n}(n \leqq 835)$, $E_{n}(n \leqq 808), B_{n}(n \leqq 836)$ to the Unpublished Mathematical Tables repository of this journal.

Section 4 shows how the formulas of Section 2 lead to some simple proofs of arithmetical properties of these numbers.

2. Formulas for Computation. The traditional method of calculating $T_{n}$ and $E_{n}$ is to use recurrence relations, such as the following: Let $\cos z=\sum_{n} \geqq_{0} C_{n} z^{n} / n$;

Received February 6, 1967.

* Supported in part by NSF Grant GP 3909. 
then the coefficient of $z^{n} / n !$ in $(\tan z)(\cos z)$ is

$$
\sum_{k}\left(\begin{array}{l}
n \\
k
\end{array}\right) T_{k} C_{n-k}
$$

and in $(\sec z)(\cos z)$ it is

$$
\sum_{k}\left(\begin{array}{c}
n \\
k
\end{array}\right) E_{k} C_{n-k}
$$

Hence, making use of the fact that $T_{2 n}=E_{2 n+1}=0$, we have the recurrence relations

(4) $\left(\begin{array}{c}2 n+1 \\ 1\end{array}\right) T_{1}-\left(\begin{array}{c}2 n+1 \\ 3\end{array}\right) T_{3}+\cdots+(-1)^{n}\left(\begin{array}{c}2 n+1 \\ 2 n+1\end{array}\right) T_{2 n+1}=1, \quad n \geqq 0$;

$$
\left(\begin{array}{c}
2 n \\
0
\end{array}\right) E_{0}-\left(\begin{array}{c}
2 n \\
2
\end{array}\right) E_{2}+\cdots+(-1)^{n}\left(\begin{array}{c}
2 n \\
2 n
\end{array}\right) E_{2 n}=0, \quad n>0 .
$$

The disadvantage of these formulas is that the binomial coefficients as well as the numbers $T_{n}, E_{n}$ become very large when $n$ is large, so a time-consuming multiplication of multiple-precision numbers is implied. As Lehmer [4] has observed, we may simplify the calculations if we remember the values of

$$
\left(\begin{array}{c}
2 n+1 \\
k
\end{array}\right) T_{k}, \quad\left(\begin{array}{c}
2 n \\
k
\end{array}\right) E_{k}
$$

so that when $n$ increases by 1 we need only multiply

$$
\left(\begin{array}{c}
2 n+1 \\
k
\end{array}\right) T_{k}
$$

by

$$
\frac{(2 n+2)(2 n+3)}{(2 n+2-k)(2 n+3-k)}
$$

to get the next value; but the method to be described here is even simpler and has other advantages.

The tangent numbers may be evaluated by noting that $D\left(\tan ^{n} z\right)$ is $n \tan ^{n-1} z\left(1+\tan ^{2} z\right)$; hence the $n$th derivative of $\tan z$ is a polynomial in $\tan z$. We have $D^{n}(\tan z)=P_{n}(\tan z)$, where the polynomials $P_{n}(x)$ are defined by

$$
P_{1}(x)=x, \quad P_{n+1}(x)=\left(1+x^{2}\right) P_{n}^{\prime}(x) .
$$

Thus if we write

$$
D^{n}(\tan z)=T_{n 0}+T_{n 1} \tan z+T_{n 2} \tan ^{2} z+\cdots
$$

the coefficients $T_{n k}$ satisfy the recurrence equation

$$
T_{0 k}=\delta_{1 k} ; \quad T_{n+1, k}=(k-1) T_{n, k-1}+(k+1) T_{n, k+1} .
$$

Since $T_{n}=\left.D^{n}(\tan z)\right|_{z=0}=T_{n 0}$, and since $T_{n k}$ is zero except for at most $(n+3) / 2$ values of $k$, formula (7) shows that the calculation of all $T_{n+1, k}$ from the values of $T_{n, k}$ essentially requires only $(n+2) / 2$ multiplications of a small number $k$ by a 
iarge number $T_{n, k}$ and $n / 2$ additions of large numbers. Since we are interested only $\ln T_{n 0}$ for odd values of $n$, we might try to use the relation

$$
T_{n+2, k}=(k-2)(k-1) T_{n, k-2}+2 k^{2} T_{n, k}+(k+1)(k+2) T_{n, k+2}
$$

but a count of the operations involved shows this provides little if any improvement over (7), and so the simpler form (7) is preferable.

Similarly, we have $D\left(\sec z \tan ^{n} z\right)=\sec z\left(n \tan ^{n-1} z+(n+1) \tan ^{n+1} z\right)$, hence if we write

$$
D^{n}(\sec z)=(\sec z)\left(E_{n 0}+E_{n 1} \tan z+E_{n 2} \tan ^{2} z+\cdots\right)
$$

we have the recurrence

$$
E_{0 k}=\delta_{0 k} ; \quad E_{n+1, k}=k E_{n, k-1}+(k+1) E_{n, k+1} .
$$

Since $E_{n}=E_{n 0}$, this relation yields an efficient method for calculating the Euler numbers. A somewhat similar recurrence relation was used by Joffe [3] to calculate Euler numbers; his method requires essentially the same amount of computation, but as explained in the next section there is a way to modify (9) to obtain a considerable advantage.

The identities $\tan (\pi / 4+z / 2)=\tan z+\sec z$ and $D^{n}(\tan (\pi / 4+z / 2))=$ $2^{-n} P_{n}(\tan (\pi / 4+z / 2))$ imply that the sums of the numbers $T_{n k}$ have a very simple form:

$$
2^{-n} P_{n}(1)=2^{-n} \sum_{k \geqq 0} T_{n k}=\left\{\begin{array}{l}
E_{n}, n \text { even }, \\
T_{n}, n \text { odd }
\end{array}\right.
$$

This relation can be used to advantage when both $E_{n}$ and $T_{n}$ are being calculated.

The definition of $\tan z$ implies

$$
\begin{aligned}
\tan z & =\frac{\sin z}{\cos z}=\frac{\left(e^{i z}-e^{-i z}\right)}{i\left(e^{i z}+e^{-i z}\right)}=\frac{1}{z}\left(\frac{2 i z}{e^{2 i z}+1}-i z\right)=\frac{1}{z}\left(\frac{2 i z}{e^{2 i z}-1}-\frac{4 i z}{e^{4 i z}-1}-i z\right) \\
& =\frac{1}{z}\left(-i z+\sum_{n \geqq 0}\left((2 i z)^{n}-(4 i z)^{n}\right) B_{n} / n !\right) ;
\end{aligned}
$$

and by equating coefficients we obtain the well-known identity

$$
B_{n}=-i^{-n} n T_{n-1} / 2^{n}\left(2^{n}-1\right), \quad n>1 .
$$

Hence, the Bernoulli numbers may be obtained from the tangent numbers by a calculation which (on a binary computer) is especially simple.

The celebrated von Staudt-Clausen theorem $[8,1]$ states that

$$
B_{2 n}=C_{2 n}-\sum_{p \text { prime } ;(p-1) \backslash 2 n} \frac{1}{p}
$$

where $C_{2 n}$ is an integer. The table appended to this paper expresses $B_{n}$ in this form, and, as shown below, the calculation of (11) may be carried out without any multiple-precision division.

3. Details of the Computation. By the recurrence (7) we may discard the value of $T_{n, k}$ once $T_{n+1, k+1}$ has been calculated, so only about $n$ of the values $T_{n, k}$ need 
to be retained in the computer memory at any one time. A further technique can be employed when the memory size has been exceeded; for example, suppose we start with the computation of $T_{n k}$ for $n \leqq 4$ :

$\begin{array}{lcccccc} & k=0 & k=1 & k=2 & k=3 & k=4 & k=5 \\ n=0 & 0 & 1 & & & & \\ n=1 & 1 & 0 & 1 & & & \\ n=2 & 0 & 2 & 0 & 2 & & \\ n=3 & 2 & 0 & 8 & 0 & 6 & \\ n=4 & 0 & 16 & 0 & 40 & 0 & 24\end{array}$

and suppose that very little memory space is available, so that we cannot completely evaluate all of the entries for $n=5$; we might obtain
$n=5 \quad 16$
0
136
0
240
0

where "*" denotes an unknown value. The calculation may still proceed, keeping track of unknown values:

$\begin{array}{rrrrrrrr}n=6 & 0 & 272 & 0 & 1232 & 0 & * & \\ n=7 & 272 & 0 & 3968 & 0 & * & & \\ n=8 & 0 & 7936 & 0 & * & & & \\ n=9 & 7936 & 0 & * & & & & \text { etc. }\end{array}$

In this way we may compute the values of about twice as many tangent numbers as were produced before overflow occurred, avoiding much of the calculation of the $T_{n, k}$.

Since the numbers $T_{n}$ become very large ( $T_{835}$ has 1866 digits, and $T_{n}$ is asymptotically $2^{n+2} n ! / \pi^{n+1}$ when $n$ is odd), care needs to be taken for storage allocation of the numbers $T_{n, k}$ if we are to make efficient use of memory space. The program we prepared makes use of two rather small areas of memory (say $A$ and $B$ ) each of which is capable of holding any one of the numbers $T_{n, k}$, plus a large number of consecutive locations used for all the remaining values. By sweeping cyclically through this large memory area, it is possible to store and retrieve the values in a simple manner.

For the sake of illustration let us suppose the word size of our computer is very small, so that only one decimal digit may be stored per word; and suppose there are just 14 words of memory used for the table of $T_{n, k}$. After the calculation of the values for $n=4$, the memory might have the following configuration:

\begin{tabular}{|c|c|}
\hline 6 & . \\
\hline
\end{tabular}

Here $P$ and $Q$ represent variables in the program that point to the current places of interest in the memory; $P$ points to the number that will be accessed next, and $Q$ points to the place where the next value is to be written. Only locations from $P$ to $Q$ contain information that will be used subsequently by the program. The symbols "." and "," represent special negative codes in the table which delimit the numbers in an obvious fashion. As we begin the calculation for $n=5$, we set area $A$ to zero and a variable $k$ to 1 . The basic cycle is then: 
(a) Set area $B$ to $k$ times the next value indicated by $P$, and move $P$ to the right.

(b) Store the value of $A+B$ into the locations indicated by $Q$, and move $Q$ to the right.

(c) Transfer the contents of $B$ to area $A$.

(d) Increase $k$ by 2 .

In the case of (13) we would change the memory configuration to

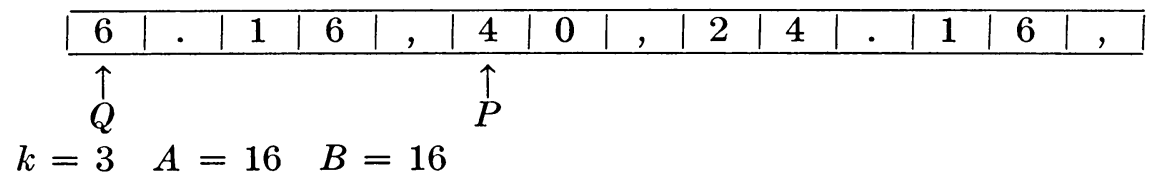

Notice that the value 16 has been stored, the pointer $Q$ has moved to the right and (treating the memory as a circular store) then to the far left. The next two iterations of steps (a) $-(d)$ give

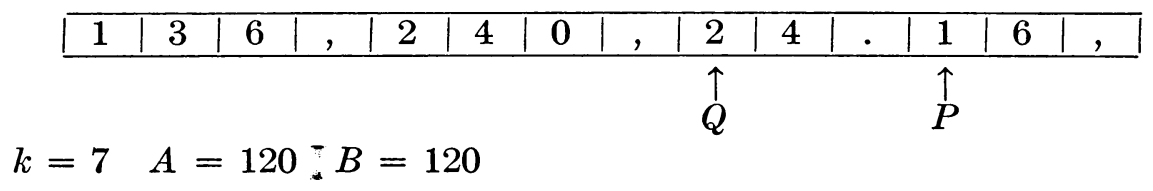

Now since the terminating "." was sensed, the program attempts to store the value from area $A$; but since this would make pointer $Q$ pass $P$, the "memory overflow" condition is sensed, and the memory configuration becomes

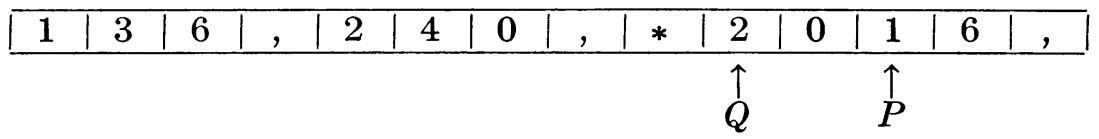

where "*" is another internal code symbol. The computation for $n=6$ is similar but it uses a different initialization since $n$ is even; after $n=6$ has been processed we would have

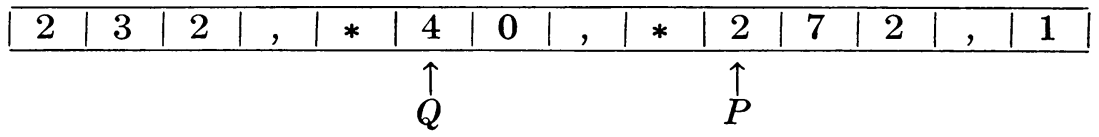

and so on.

The above discussion has been slightly simplified for purposes of exposition. In the actual program, it is preferable to keep the numbers stored with least significant digit first, so that for example (16) would really be

\begin{tabular}{|c|c|c|c|c|c|c|c|c|c|c|c|c|c|}
\hline 6 & 3 & 1 &, & 0 & 4 & 2 &, & $*$ & 2 & 1 & 6 & 1 &, \\
\hline \multicolumn{1}{c}{} \\
\hline
\end{tabular}

in order to simplify the multiple-precision operations. A few other changes in the sequence of operations were made in order to use memory a little more efficiently (for example the value $T_{n 0}$ need never be retained).

A similar method may be used for $E_{n}$. This arrangement of the computation gives a substantial advantage over Joffe's method [3] because of the "**", and it 
also has advantages over (10) for the same reason.

It remains to consider the calculation of the Bernoulli number $B_{2 n}$ from $T_{2 n-1}$. Consider formula (12); if $p$ is an odd prime, $2^{p-1} \equiv 1$ (modulo $p$ ), hence if $(p-1) \backslash 2 n$, then $2^{2 n}-1$ is divisible by $p$. So we first compute the integer

$$
N=(-1)^{n-1} 2 n T_{2 n-1}+\sum_{p \text { prime } ;(p-1) \backslash 2 n} \frac{(2 n)\left(2^{2 n}\right)\left(2^{2 n}-1\right)}{p}
$$

by referring to an auxiliary table of primes that may be calculated at the beginning of the program. Then it is merely a question of computing

$$
C_{2 n}=N / 2^{2 n}\left(2^{2 n}-1\right)=N / 2^{4 n}+N / 2^{6 n}+N / 2^{8 n}+\cdots .
$$

The calculation of $N / 2^{k}$ is of course merely a "shift right" operation in a binary computer, so all the terms of the infinite series on the right side of (20) are readily computed. This series converges very rapidly, and we know $C_{2 n}$ is an integer, so we need only carry out the calculation indicated in (20) until it converges one wordsize (35 bits) to the right of the decimal point. It is simple to check at the same time that $C_{2 n}$ is indeed very close to an integer, in order to verify the computations.

4. Periodicity of the Sequences. Examination of the tables produced by the computer program shows that the unit's digits of the nonzero tangent numbers repeat endlessly in the pattern $2,6,2,6,2,6$, starting with $T_{3}$; furthermore the two least significant digits ultimately form a repeating period of length 10:16, 72, 36, 92, $56,12,76,32,96,52,16,72, \ldots$ The three least significant digits have a period of length 50, and for four digits the period-length is 250 . These empirical observations suggest that theoretical investigation of period-length might prove fruitful.

Theorem 1. Let $p$ be an odd prime, and let $\lambda$ be the period-length of the sequence $\left\langle T_{n} \bmod p\right\rangle$. Then

$$
\lambda= \begin{cases}p-1, & p \equiv 1(\bmod 4) \\ 2(p-1), & p \equiv 3(\bmod 4)\end{cases}
$$

and

$$
T_{n+\lambda} \equiv T_{n}(\bmod p) \text { for all } n \geqq 0 .
$$

Proof. It is clear from the recurrence relation (7) that the sequence $\left\langle T_{n} \bmod p\right\rangle$ is determined by the recurrence equation

$$
y_{n+1}=A y_{n}
$$

where the vector $y_{n}$ and the matrix $A$ are defined by

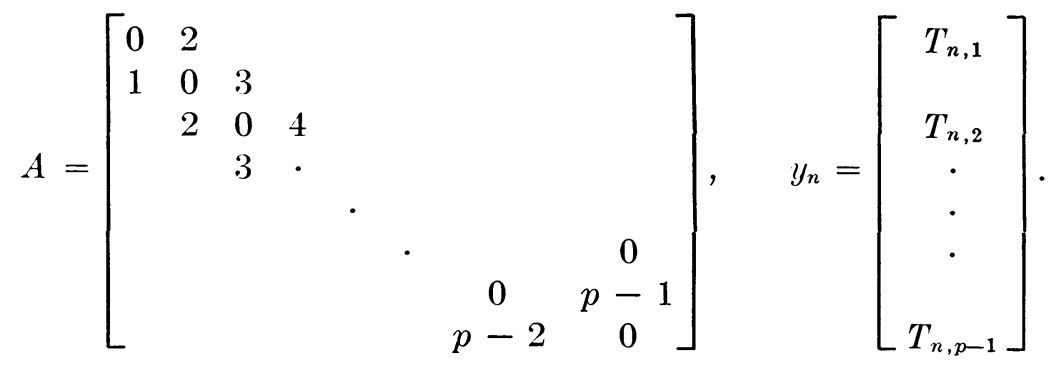


For $T_{n, k}$ can contribute nothing to any subsequent value of $T_{n}$ when $k \geqq p$.

We will show below that the minimum polynomial equation satisfied by $A$ is

$$
\left.A^{p-1}-(-1)^{(p-1) / 2} I \equiv 0 \text { (modulo } p\right) ;
$$

hence (22) is valid for the value of $\lambda$ given by (21). It remains to show that $\lambda$ is the true period-length of the sequence, not merely a multiple of the period.

Accordingly, suppose $T_{n+\lambda^{\prime}} \equiv T_{n}(\bmod p)$ for some positive $\lambda^{\prime} \leqq \lambda$ and all large $n$. In view of (22) this congruence must hold for all $n \geqq 0$. Let $y=y_{\lambda^{\prime}}-y_{0}$; then $p\left(A^{n} y\right) \equiv 0$ for all $n \geqq 0$ where $p$ denotes the projection onto the first component of the vector $A^{n} y$. But this implies $n ! \alpha_{n} \equiv 0(\bmod p)$ for all components $\alpha_{n}$ of $y$, hence $y \equiv 0$, i.e., $y_{0} \equiv y_{\lambda^{\prime}}=A^{\lambda^{\prime}} y_{0}$. It follows that $y_{n} \equiv A^{\lambda^{\prime}} y_{n}$ for all $n \geqq 0$, and since the vectors $y_{0}, \cdots, y_{p-2}$ are obviously linearly independent we must have $A^{\lambda^{\prime}} \equiv I$ (modulo $p$ ). Therefore, $\lambda^{\prime}$ is $\geqq \lambda$, and the proof is complete.

It remains to verify (25), which seems to be a nontrivial identity. Clearly, the minimum polynomial of $A$ must be of degree $p-1$, since $y_{0}, \cdots, y_{p-2}$ are linearly independent; therefore, it suffices to calculate the characteristic polynomial of $A$. Let

$$
D_{n}=\operatorname{det}\left[\begin{array}{ccccccc}
x & -(n-1) & & & & & \\
-n & x & -(n-2) & & & \\
& -(n-1) & \cdot & & & & \\
& & & & \cdot & & \\
& & & & & x & -1 \\
& & & & & -2 & x
\end{array}\right] \text {; }
$$

then $D_{n}=x D_{n-1}-(n-1) n D_{n-2}$ so we have

$$
\begin{aligned}
& D_{1}=x, \\
& D_{2}=x^{2}-1 \cdot 2, \\
& D_{3}=x^{3}-(1 \cdot 2+2 \cdot 3) x, \\
& D_{4}=x^{4}-(1 \cdot 2+2 \cdot 3+3 \cdot 4) x^{2}+1 \cdot 2 \cdot 3 \cdot 4, \\
& D_{5}=x^{5}-(1 \cdot 2+2 \cdot 3+3 \cdot 4+4 \cdot 5) x^{3}+(1 \cdot 2 \cdot 3 \cdot 4+1 \cdot 2 \cdot 4 \cdot 5+2 \cdot 3 \cdot 4 \cdot 5) x,
\end{aligned}
$$

and in general

$$
D_{n}=x^{n}-s_{n 1} x^{n-2}+s_{n 2} x^{n-4}-s_{n 3} x^{n-6}+\cdots,
$$

where

$$
s_{n k}=\sum a_{1}\left(a_{1}+1\right) a_{2}\left(a_{2}+1\right) \cdots a_{k}\left(a_{k}+1\right)
$$

is summed over all values $1 \leqq a_{1} \ll a_{2} \ll \cdots \ll a_{k}<n$. (Here $u \ll v$, for integers $u$, v, denotes $v \geqq u+2$.) Thus, $s_{n k}$ is the sum of all products of $k$ of the pairs $1 \cdot 2,2 \cdot 3, \cdots,(n-1) \cdot n$ with no "overlapping" pairs allowed in the same term.

To evaluate $s_{(p-1) k} \bmod p$, it is convenient to allow also the pairs $(p-1) \cdot p$ and $p \cdot 1$, since these contribute nothing to the sum. Thus for example, 


$$
\begin{aligned}
s_{62} \equiv & 1 \cdot 2 \cdot 3 \cdot 4+1 \cdot 2 \cdot 4 \cdot 5+1 \cdot 2 \cdot 5 \cdot 6+1 \cdot 2 \cdot 6 \cdot 7+2 \cdot 3 \cdot 4 \cdot 5+2 \cdot 3 \cdot 5 \cdot 6 \\
& +2 \cdot 3 \cdot 6 \cdot 7+2 \cdot 3 \cdot 7 \cdot 1+3 \cdot 4 \cdot 5 \cdot 6+3 \cdot 4 \cdot 6 \cdot 7+3 \cdot 4 \cdot 7 \cdot 1 \\
& +4 \cdot 5 \cdot 6 \cdot 7+4 \cdot 5 \cdot 7 \cdot 1+5 \cdot 6 \cdot 7 \cdot 1
\end{aligned}
$$

(modulo 7). Let us say two terms $a_{1}\left(a_{1}+1\right) \cdots a_{k}\left(a_{k}+1\right)$ and $a_{1}{ }^{\prime}\left(a_{1}{ }^{\prime}+1\right) \cdots$ $a_{k}{ }^{\prime}\left(a_{k}{ }^{\prime}+1\right)$ are "equivalent" if, for some $r$ and $t$ and for all $j, a_{j} \equiv a^{\prime}{ }_{(j+r) \bmod p}+t$; thus, in the above example the terms $1 \cdot 2 \cdot 4 \cdot 5,2 \cdot 3 \cdot 5 \cdot 6,3 \cdot 4 \cdot 6 \cdot 7,4 \cdot 5 \cdot 7 \cdot 1$, $5 \cdot 6 \cdot 1 \cdot 2,6 \cdot 7 \cdot 2 \cdot 3,7 \cdot 1 \cdot 3 \cdot 4$ are mutually equivalent. It is impossible for a term to be equivalent to itself when $0<t<p$, since this would imply $a_{1}+\cdots+a_{k}$ $\equiv a_{1}+\cdots+a_{k}+k t$, and $t \equiv 0$. Therefore, each equivalence class has precisely $p$ terms in it. When $k<(p-1) / 2$ the sum over an equivalence class has the form

$$
\sum_{0 \leqq t<p}\left(a_{1}+t\right)\left(a_{1}+t+1\right) \cdots\left(a_{k}+t\right)\left(a_{k}+t+1\right)
$$

where the summand is a polynomial of degree $\leqq p-2$ in $t$. Any such summation may be expressed modulo $p$ as a sum of terms of the form

$$
c \sum_{0 \leqq t<p}\left(\begin{array}{c}
t \\
j
\end{array}\right)=c\left(\begin{array}{c}
p \\
j+1
\end{array}\right) \equiv 0, \text { since } 0 \leqq j<p-1,
$$

so $s_{k p} \equiv 0$. It follows that

$$
D_{p-1} \equiv x^{p-1}+(-1)^{(p-1) / 2}(p-1) !(\text { modulo } p)
$$

and an application of Wilson's theorem completes the proof of (25).

Theorem 2. Let $p$ be an odd prime, and let $\lambda$ be the period-length of the sequence $\left\langle E_{n} \bmod p\right\rangle$. Then

$$
\lambda= \begin{cases}p-1, & p \equiv 1(\bmod 4) \\ 2(p-1), & p \equiv 3(\bmod 4)\end{cases}
$$

and

$$
E_{n+\lambda} \equiv E_{n}(\bmod p) \quad \text { for all } n \geqq 1 .
$$

Proof. Make the following changes in the proof of Theorem 1:

$$
A=\left[\begin{array}{rrrrrrr}
0 & 1 & & & & & \\
1 & 0 & 2 & & & & \\
& 2 & 0 & 3 & & & \\
& & 3 & \cdot & & & \\
& & & & & \\
& & & & & p-1 & 0
\end{array}\right], \quad y_{n}=\left[\begin{array}{c}
E_{n, 0} \\
\\
E_{n, 1} \\
\vdots \\
E_{n, p-1}
\end{array}\right] .
$$

Then the minimum polynomial equation satisfied by $A$ is

$$
A^{p}-(-1)^{(p-1) / 2} A \equiv 0 \text { (modulo } p \text { ). }
$$

The proof is a straightforward modification of the proof of Theorem 1.

The congruences (22) and (31) were obtained long ago by Kummer (see for example [5, p. 270]), but it was not shown that the true period-length could not be a proper divisor of the number $\lambda$ given by (21), (30). More general congruences given 
by Kummer make it possible to establish further results about the period-length:

Theorem 3. Let $p$ be an odd prime, and let $\lambda$ be given by (30). Then

$$
\begin{array}{ll}
T_{n+\lambda p^{k-1}} \equiv T_{n}\left(\operatorname{modulo} p^{k}\right), & n \geqq k, \\
E_{n+\lambda p^{k-1}} \equiv E_{n}\left(\operatorname{modulo} p^{k}\right), & n \geqq k .
\end{array}
$$

Proof. Assume $n \geqq k$ and define the sequence $\left\langle u_{m}\right\rangle$ by the rule

$$
u_{m}=(-1)^{(p-1) m / 2} T_{n+(p-1) m}, \quad m \geqq 0 .
$$

Kummer's congruence for the tangent numbers may be written

$$
\Delta^{k} u_{m} \equiv 0\left(\operatorname{modulo} p^{k}\right), \quad m \geqq 0, \quad k \geqq 1,
$$

where $\Delta^{k} u_{m}$ denotes

$$
u_{m+k}-\left(\begin{array}{c}
k \\
1
\end{array}\right) u_{m+k-1}+\left(\begin{array}{c}
k \\
2
\end{array}\right) u_{m+k-2}-\cdots+(-1)^{k} u_{m} .
$$

We will prove that (37) implies

$$
u_{m+p^{r-1}} \equiv u_{m}\left(\operatorname{modulo} p^{r}\right), \quad m \geqq 0, \quad r \geqq 1,
$$

and this will establish (34). Eq. (35) follows in the same way if we let

$$
u_{m}=(-1)^{(p-1) m / 2} E_{n+(p-1) m} .
$$

Assume Eq. (37) is valid for some sequence of real numbers (not necessarily integers) $u_{0}, u_{1}, \cdots$; thus, $\Delta^{k} u_{m}$ is an integer multiple of $p^{k}$ when $k \geqq 1$, but not necessarily when $k=0$. We will prove that the sequence $u_{m} / p, u_{m+p} / p, u_{m+2 p} / p, \cdots$, for fixed $m$ also satisfies Eq. (37), and this suffices to prove (38) by induction on $r$.

Let $E$ be the operator $E u_{m}=u_{m+1}$. Eq. (37) may be written $(E-1)^{k} u_{m} \equiv 0$ $\left(\right.$ modulo $p^{k}$ ), and our goal as stated in the preceding paragraph is to show that $\left(E^{p}-1\right)^{k}\left(u_{m} / p\right) \equiv 0$ (modulo $\left.p^{k}\right)$, i.e. $\left(E^{p}-1\right)^{k} u_{m} \equiv 0$ (modulo $\left.p^{k+1}\right)$. Let $f(E)=E^{p-2}+2 E^{p-3}+\cdots+(p-2) E+(p-1)$; then $E^{p}-1=$ $(E-1)(p+f(E)(E-1))$, hence

$$
\left(E^{p}-1\right)^{k} u_{m}=\sum_{0 \leqq j \leqq k}\left(\begin{array}{l}
k \\
j
\end{array}\right) p^{j}(E-1)^{2 k-j} f(E)^{k-j} u_{m}
$$

and each term in the sum on the right is an integer multiple of $p^{2 k}$. Hence, we have proved in fact that $\left(E^{p}-1\right)^{k} u_{m} \equiv 0$ (modulo $p^{2 k}$ ), which is more than enough to complete the proof of the theorem.

Note that Eqs. (34), (35) do not necessarily give the true period-length of the sequence $\bmod p^{k}$ when $k>1$; although (34) is "best possible" when $p=5$ and $k=2,3,4$, the tangent numbers have the same period-length modulo 9 as they do modulo 3 .

The tangent number $T_{2 n+1}$ is divisible by $2^{n}$, so the period length of $T_{n} \bmod 2^{r}$ is 1 for all $r$. Eq. (35) is valid for $\lambda=2$ when $p=2$, since Kummer's congruence (37) holds for $u_{m}=E_{n+2 m}$. In particular, we may combine the results proved above to show that for any modulus $m$ the sequences $T_{n} \bmod m, E_{n} \bmod m$ are periodic, and the period-length divides $2 \phi(m)$. 


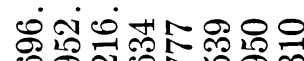
ภำ

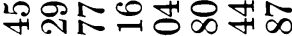

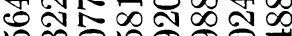
m เి

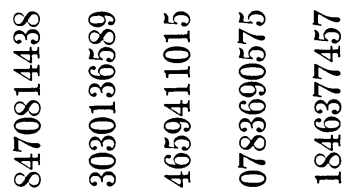

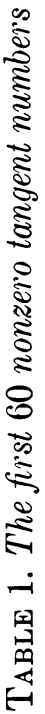
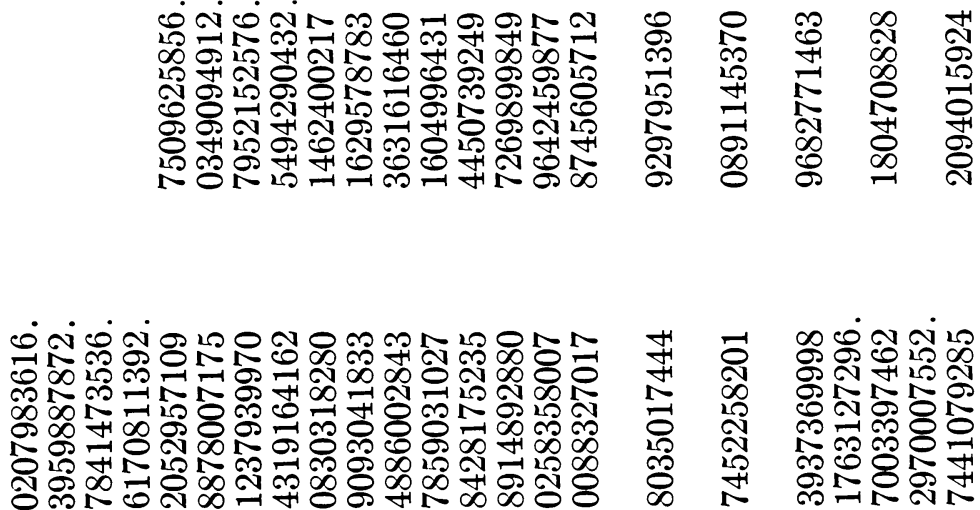

ஸ்

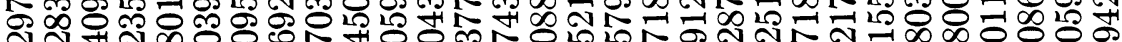

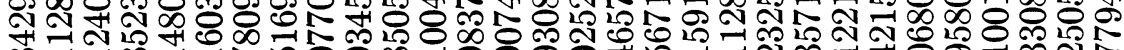
ल 구 in

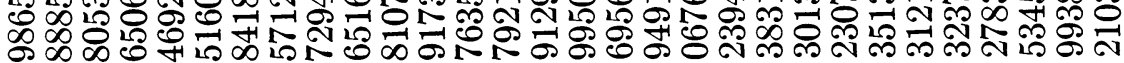

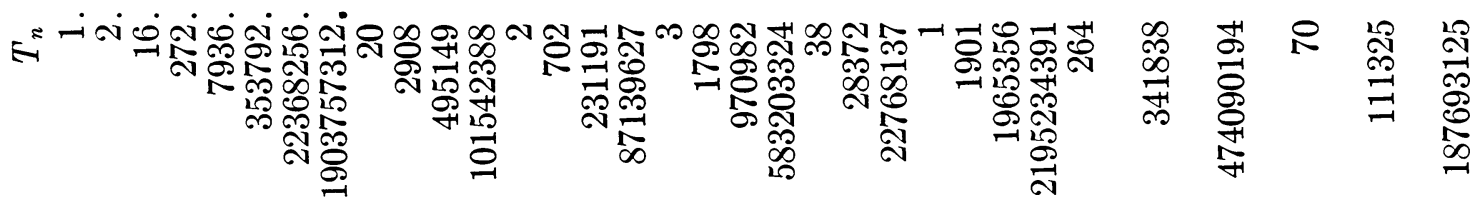

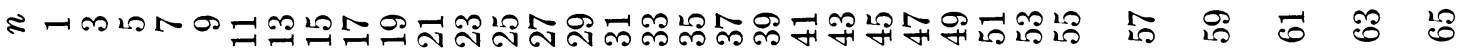




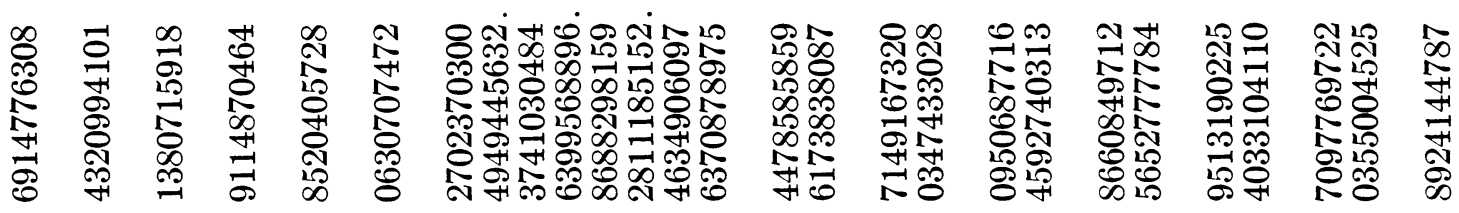

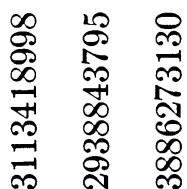

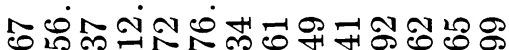

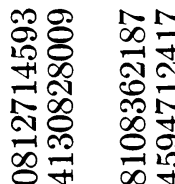

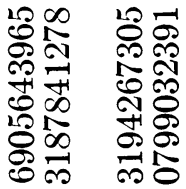

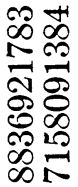

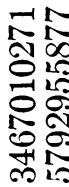

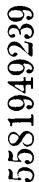

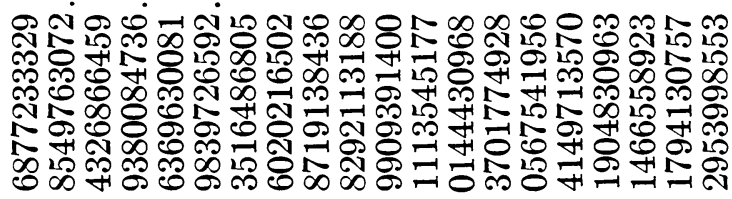

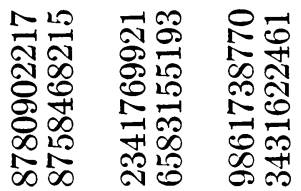

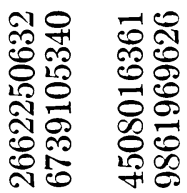

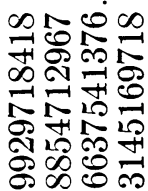

인 不 ๓⿴囗十⺝

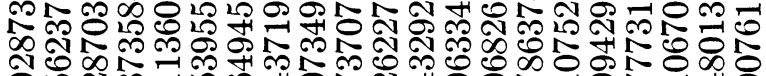

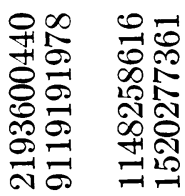

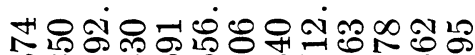
N N ิㅜㅇㅔ พิ

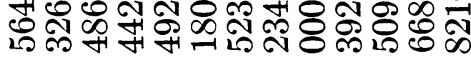

ชื

No $=$

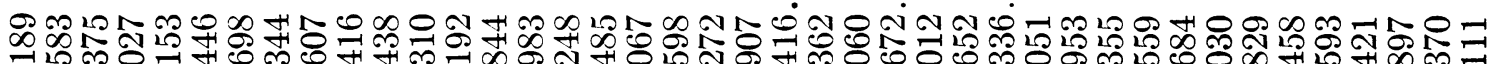

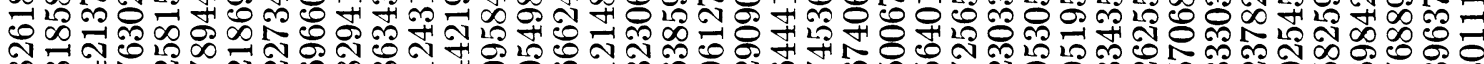
N

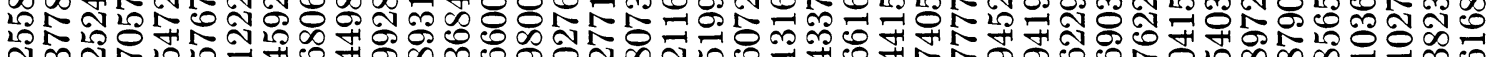

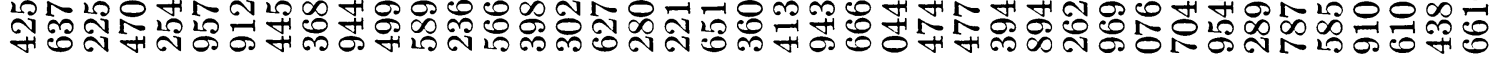

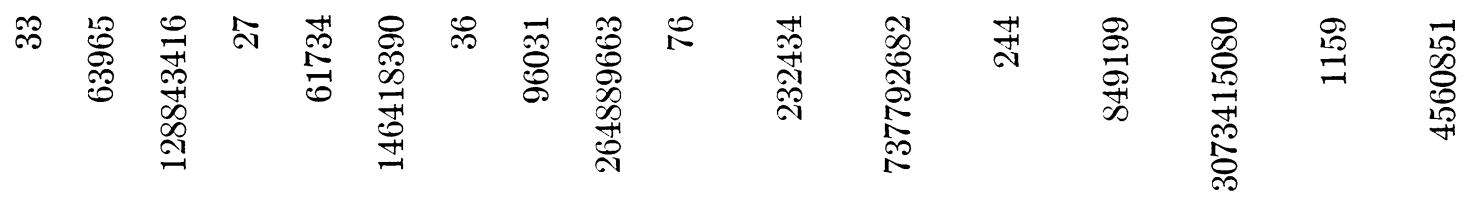

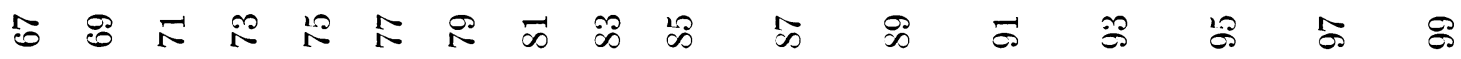




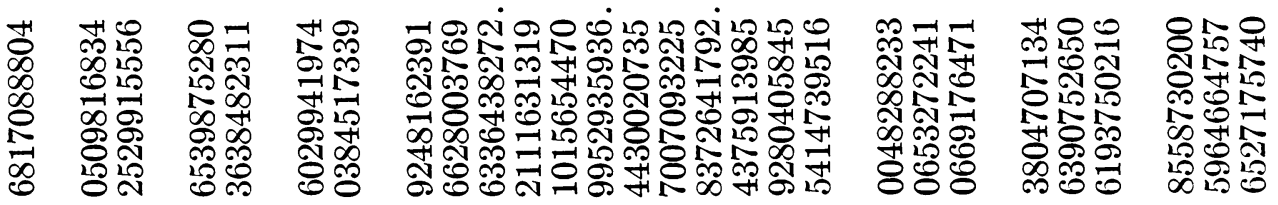

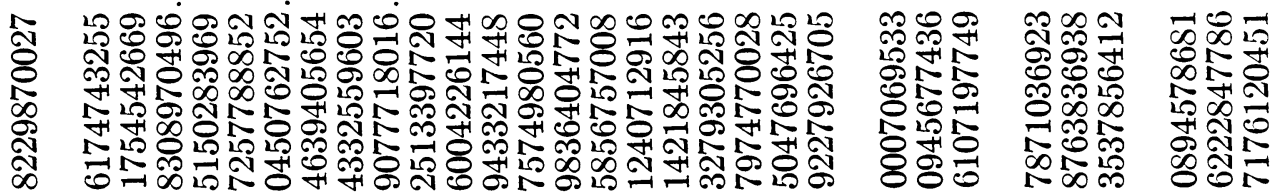

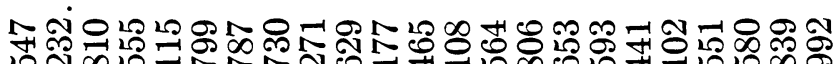
4 잉

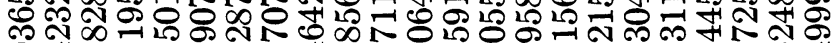

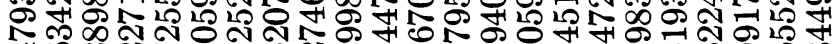
궁

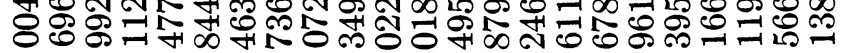

$-10$ \&. ๓ัต 07 年 स सम

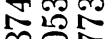

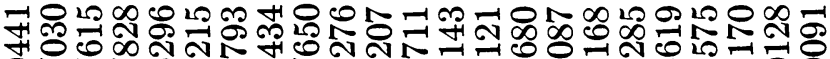

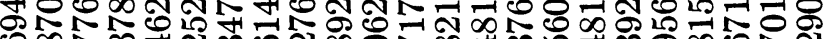

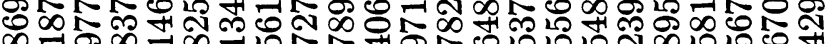

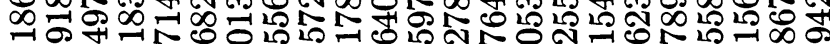

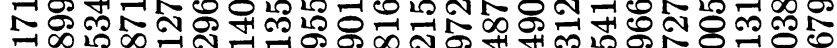

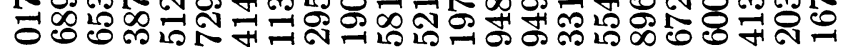

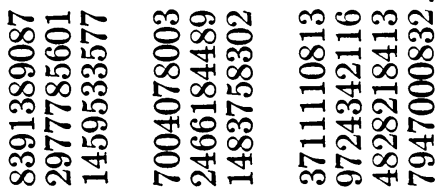

ఝ

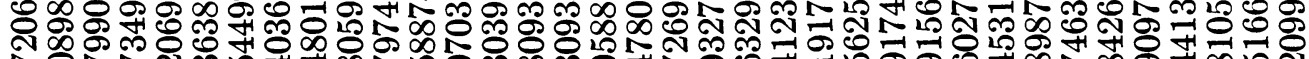
No요유.

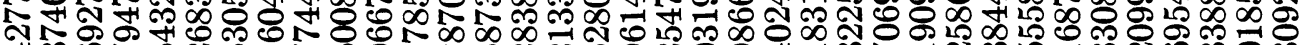
N. 붕요유

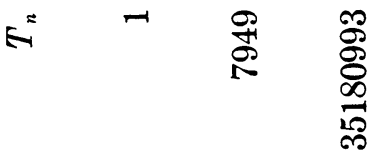

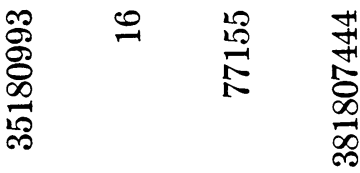

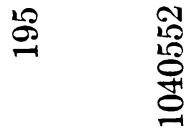

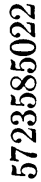
กิ่
\&

의 응 의 응 引



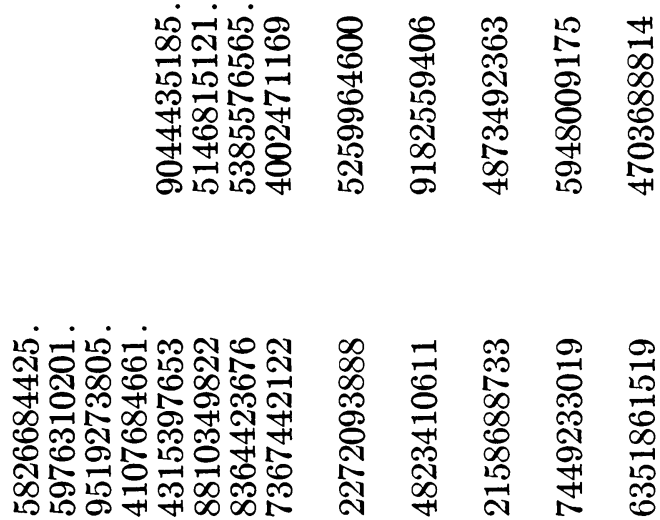

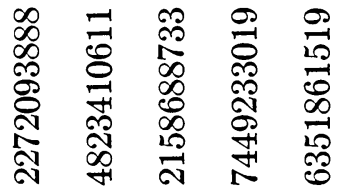

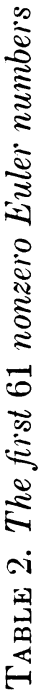
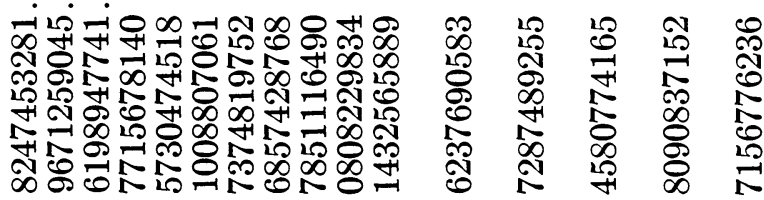

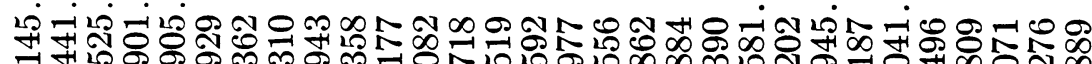

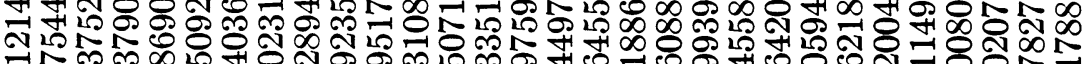
슨

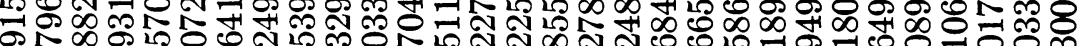

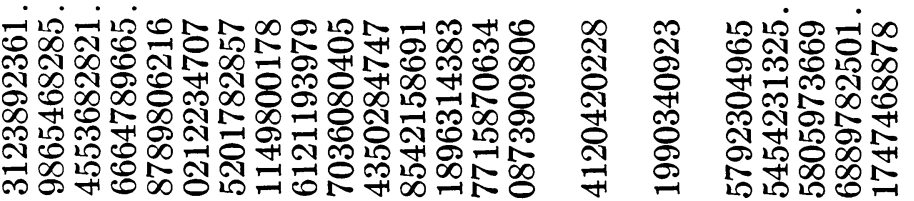

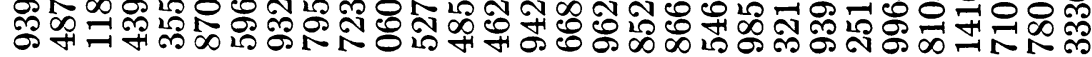

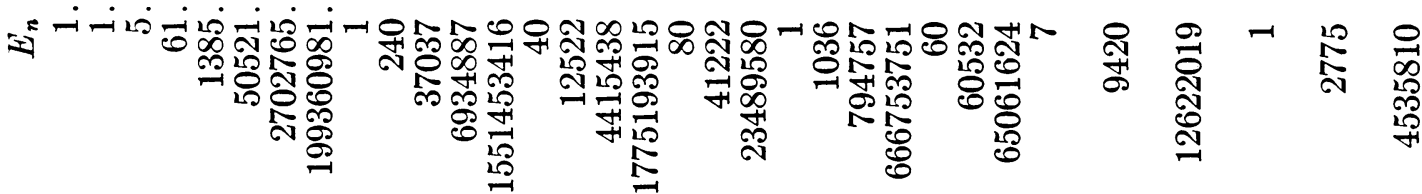

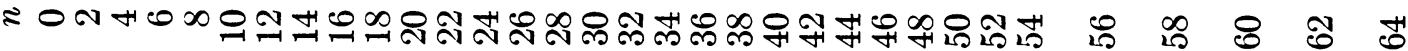




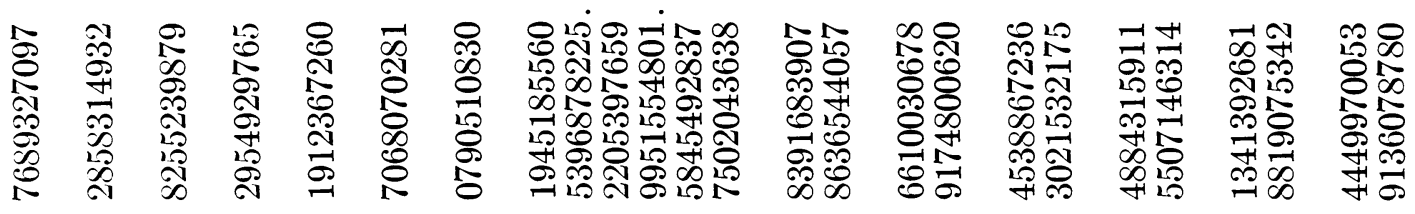

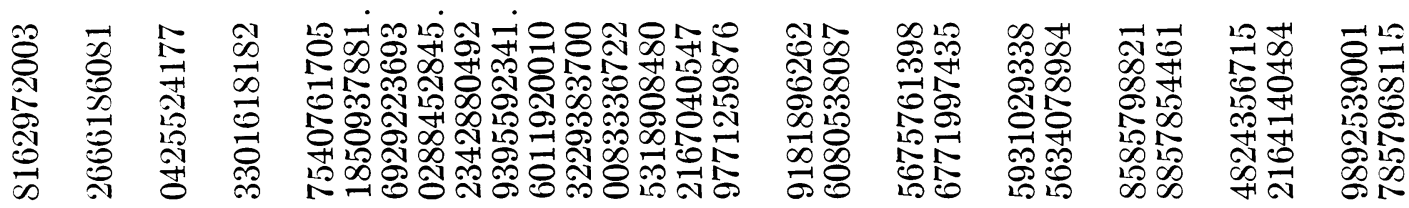

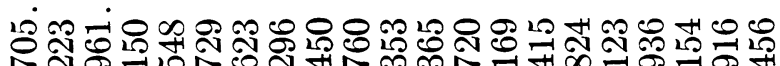

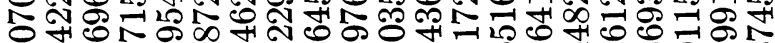

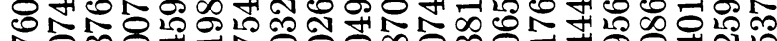

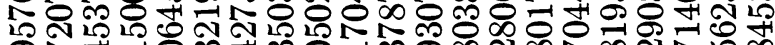
군

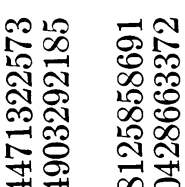

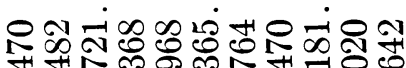
겅ำ

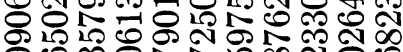

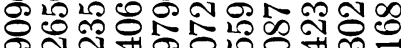

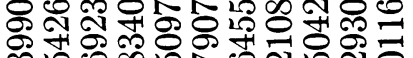
ᄋㅇㅇ용ㅇㅇ लL

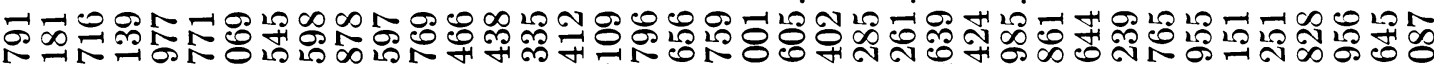

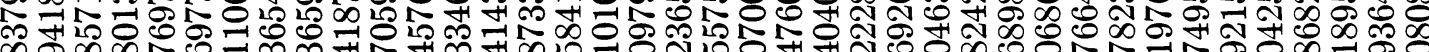
$\infty$ 잉

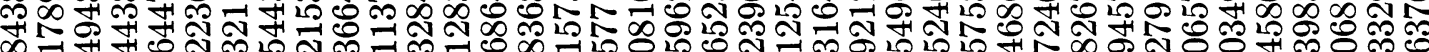

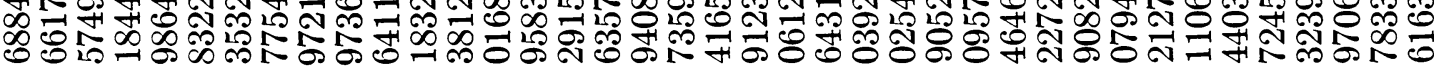

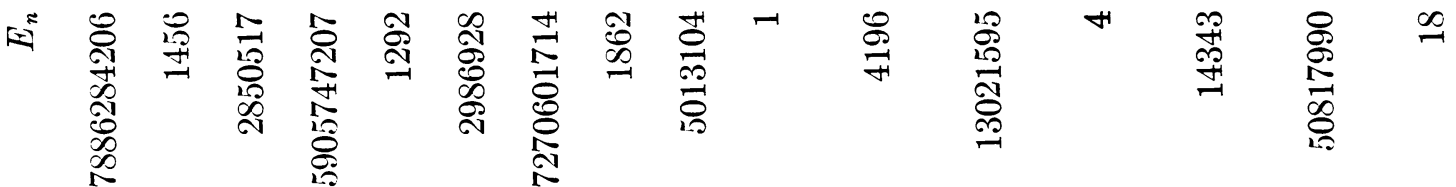

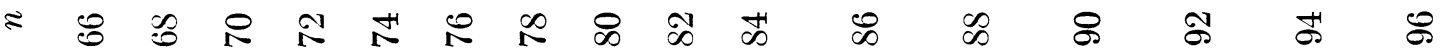




\begin{tabular}{|c|c|c|c|c|c|c|c|}
\hline 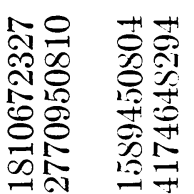 & 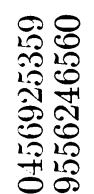 & 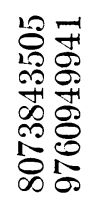 & 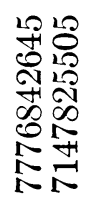 & 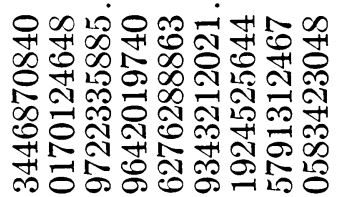 & 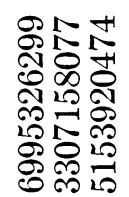 & 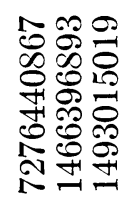 & 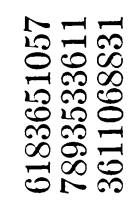 \\
\hline
\end{tabular}

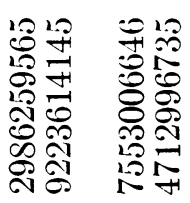

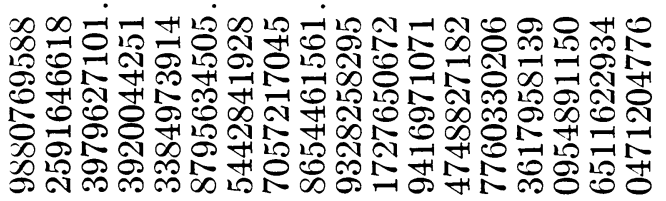

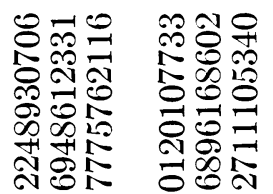

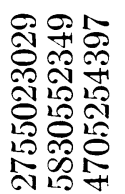

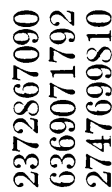

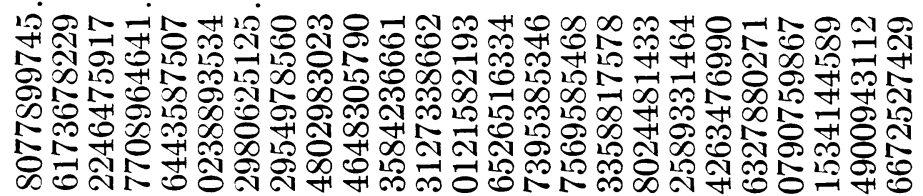

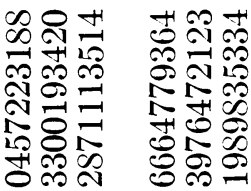

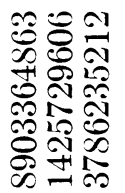

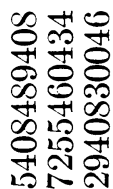

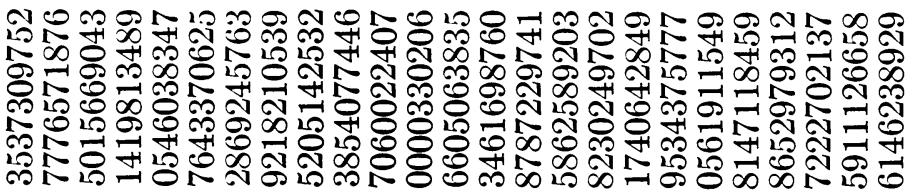

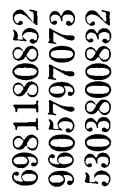

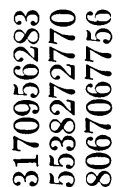

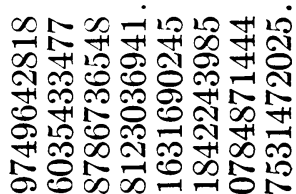

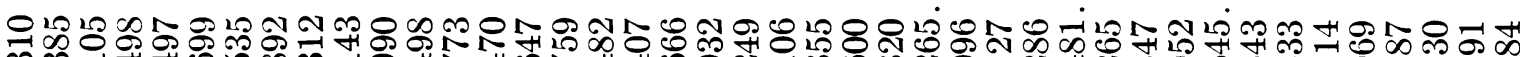
m

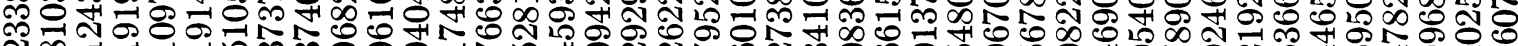
ฟै.

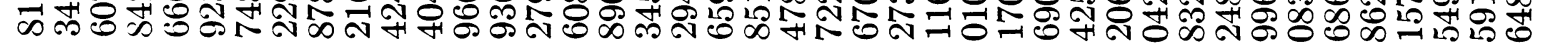

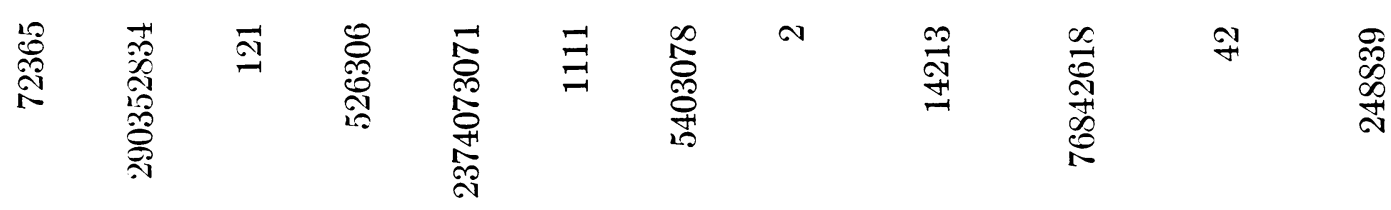

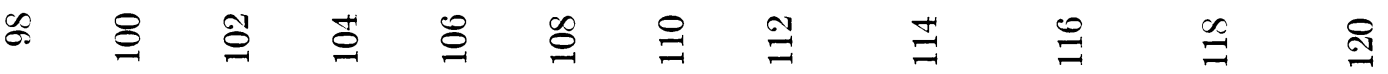




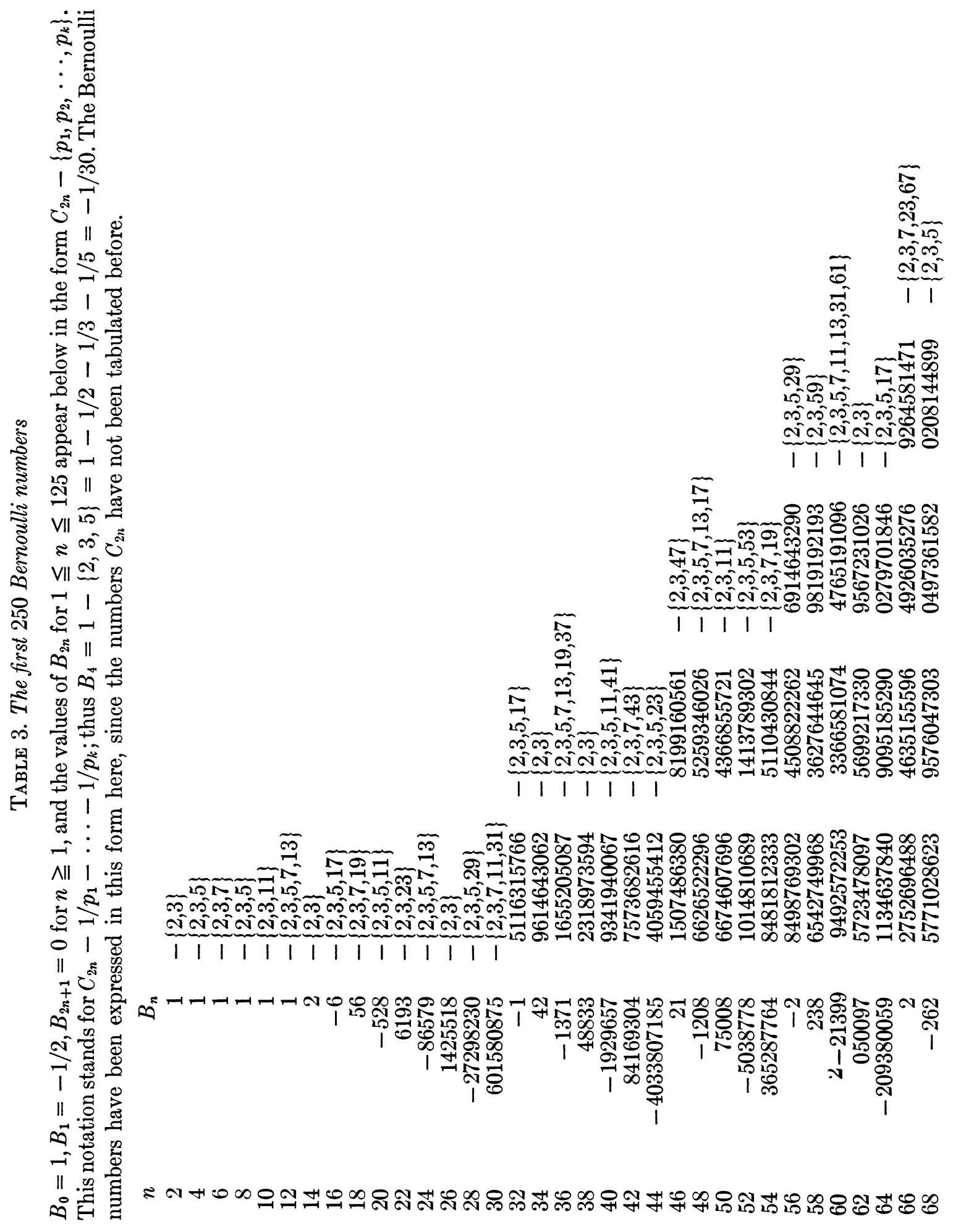



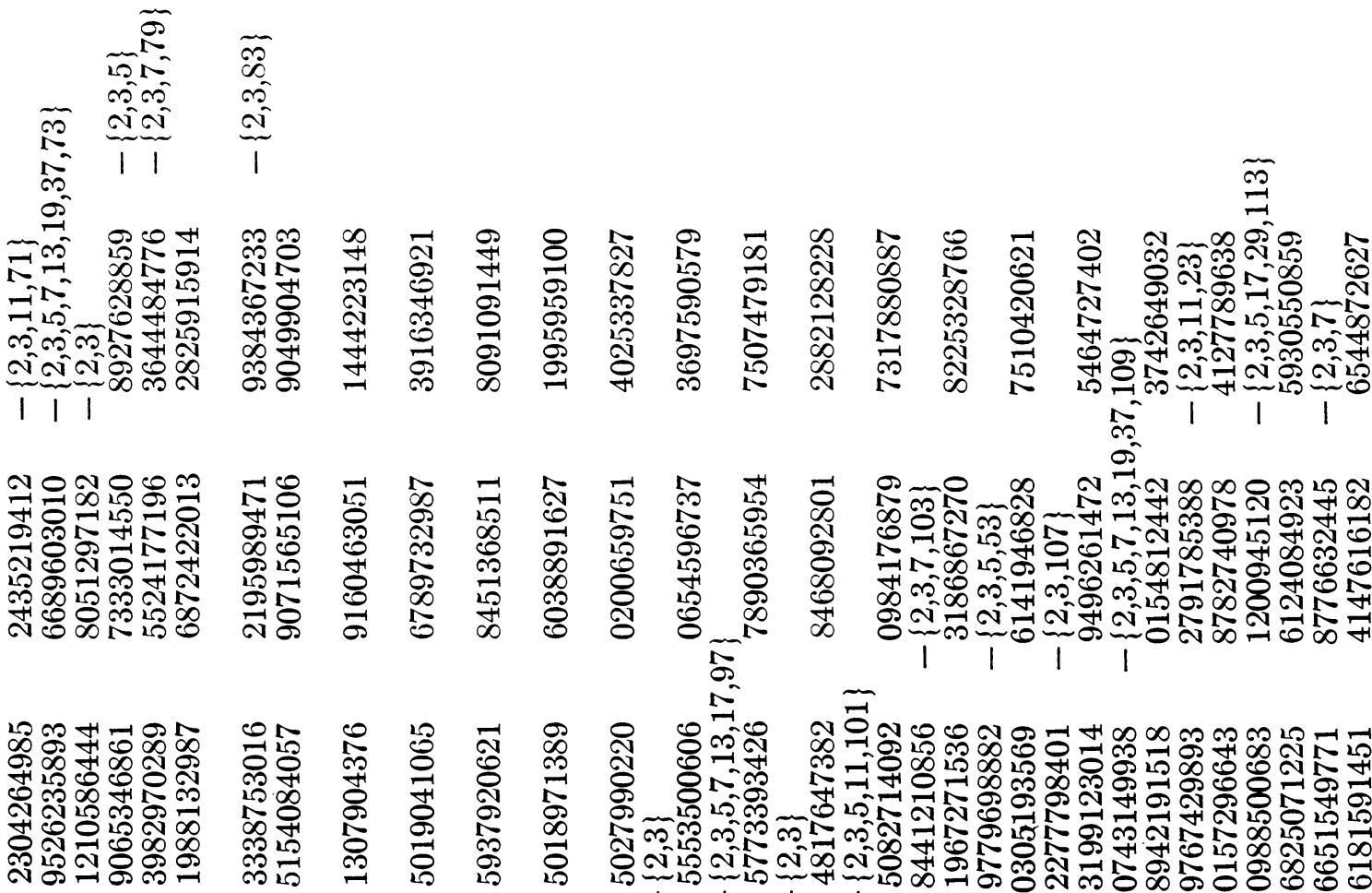

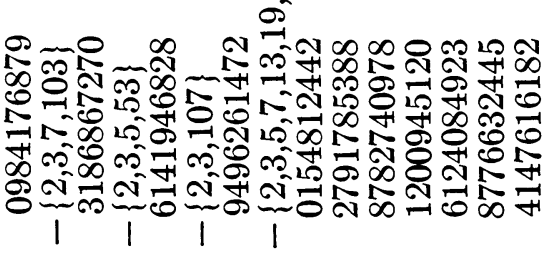
$\widetilde{N}$ N

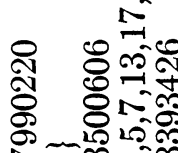
พิธ్-

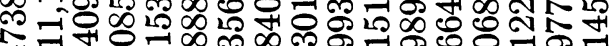
屯 mल m ผ

$$
\text { ले }
$$

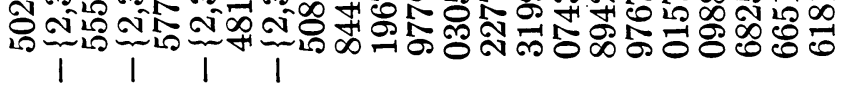

면유 廿 สํำ

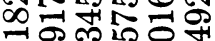
బิ ஸิ
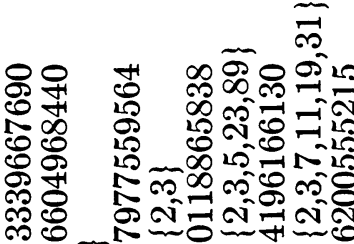

$\infty$ क्ष m. i N

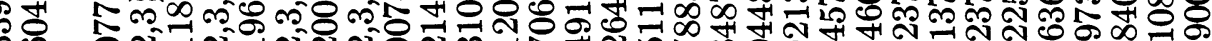
ตอ S स

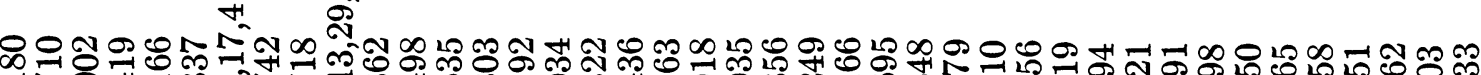

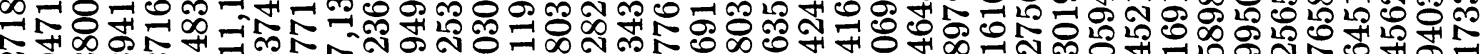

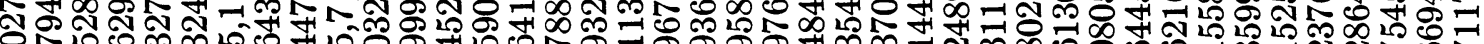
응 న్ర

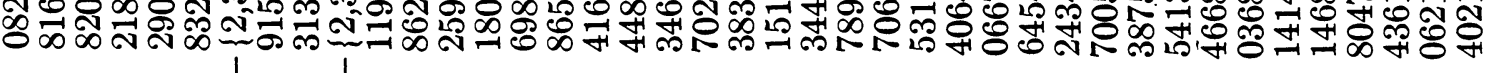

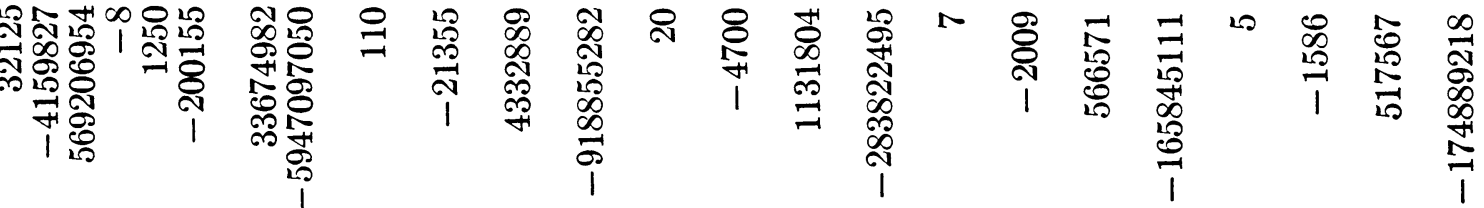

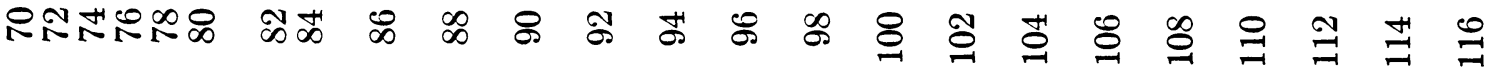


$\underbrace{\pi}_{1} \quad \frac{\tilde{m}}{\tilde{n}}$

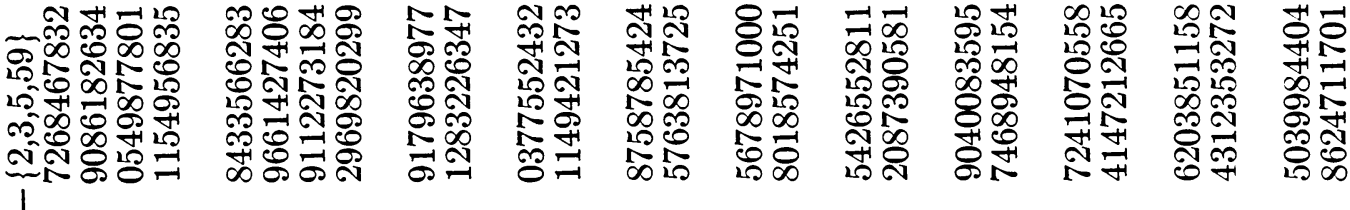

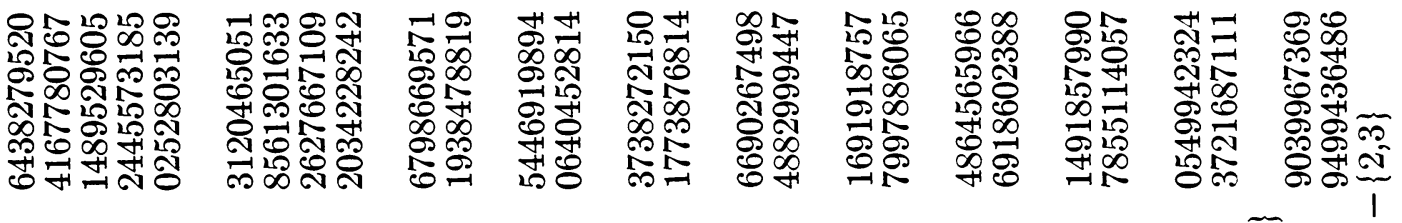

\begin{tabular}{|c|c|c|c|c|}
\hline 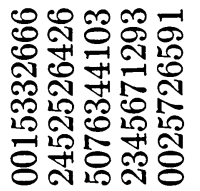 & 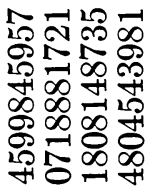 & 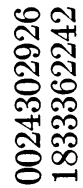 & 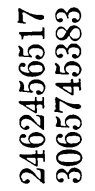 & 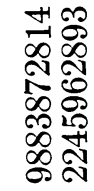 \\
\hline
\end{tabular}

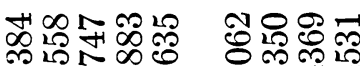
โ

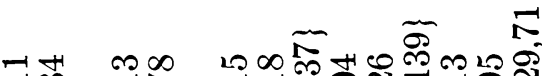

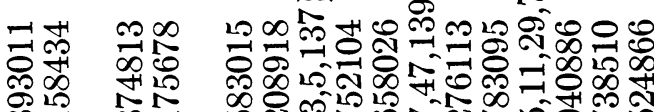

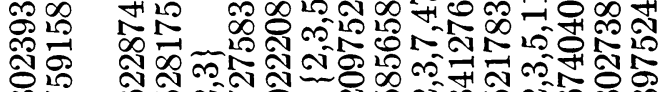

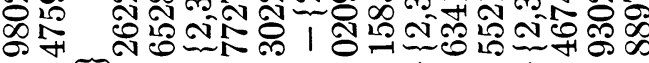
1

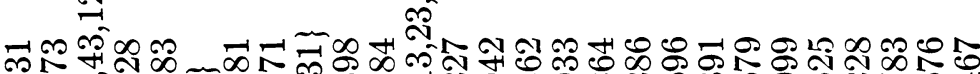

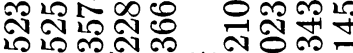
బิ

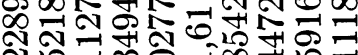
ง ल की

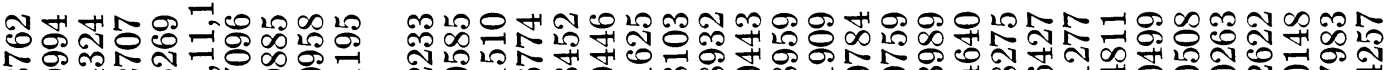
Nom

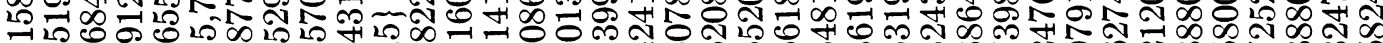

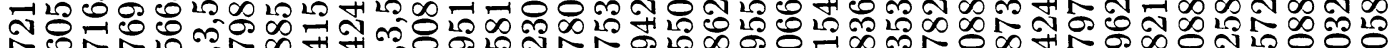
은산

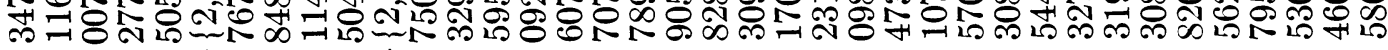
$\infty$ 건 $\infty$ 는 พ ก

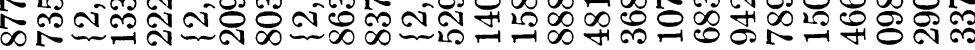
। 1 । I

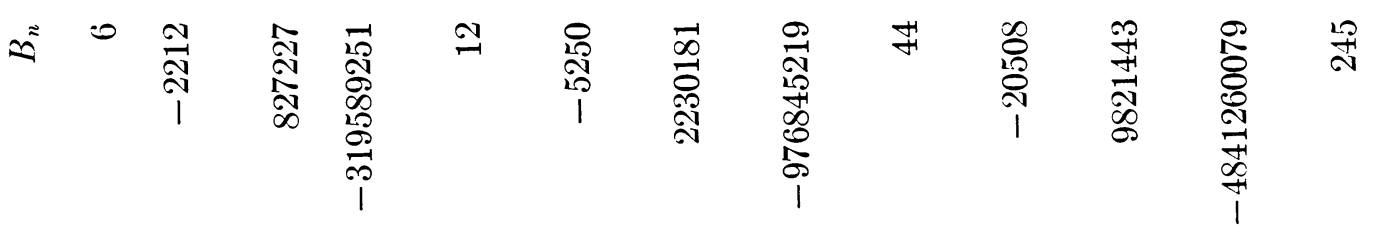

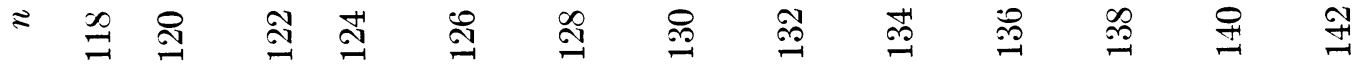


$\sqrt{20}$

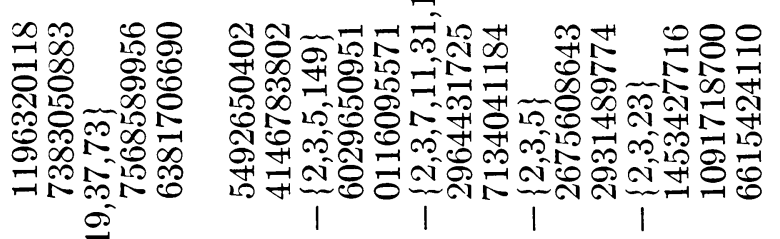
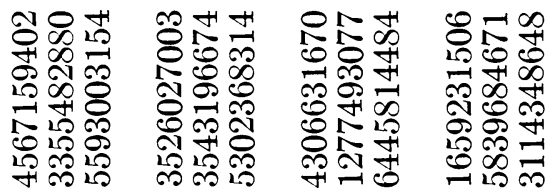

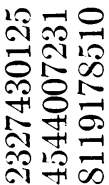
N

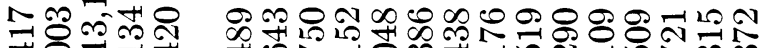

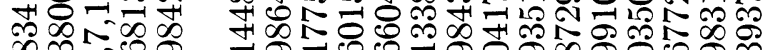
๑

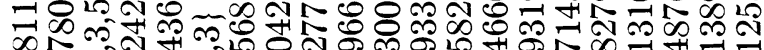

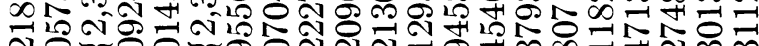

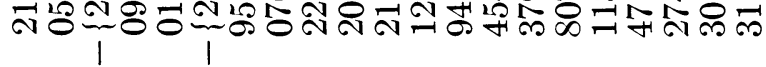

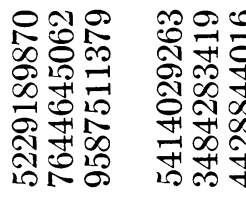

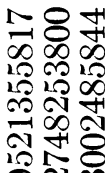

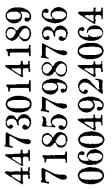

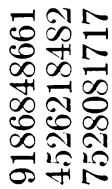

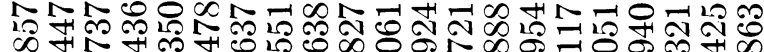
N

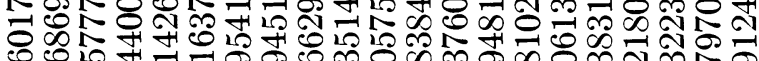
N

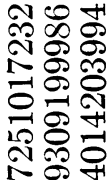

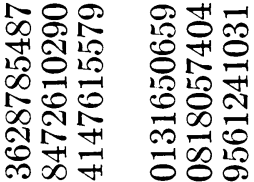

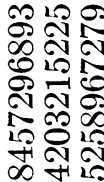

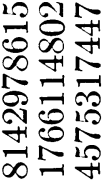

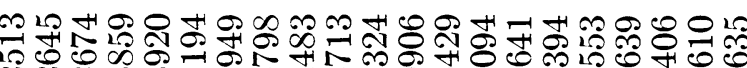

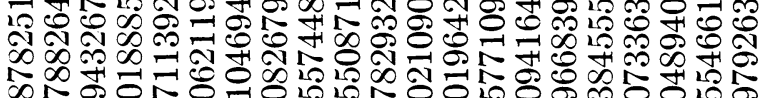

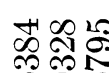

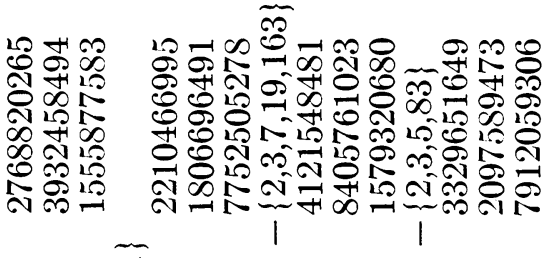
T 12 है<smiles>[Te]=[Te]</smiles>

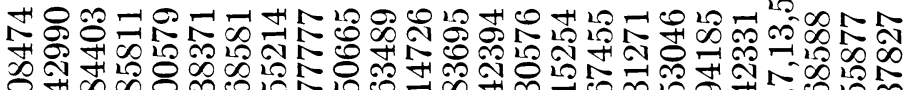

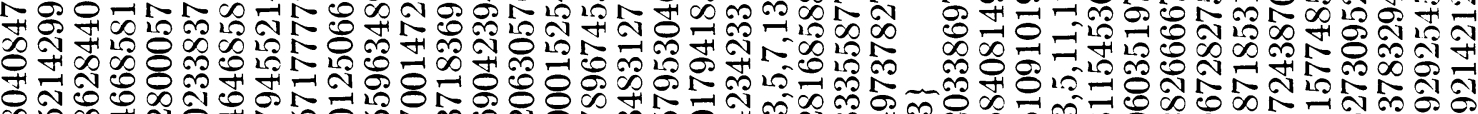
on 0 4 잉의 च

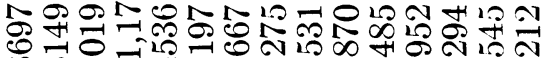

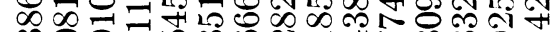
।

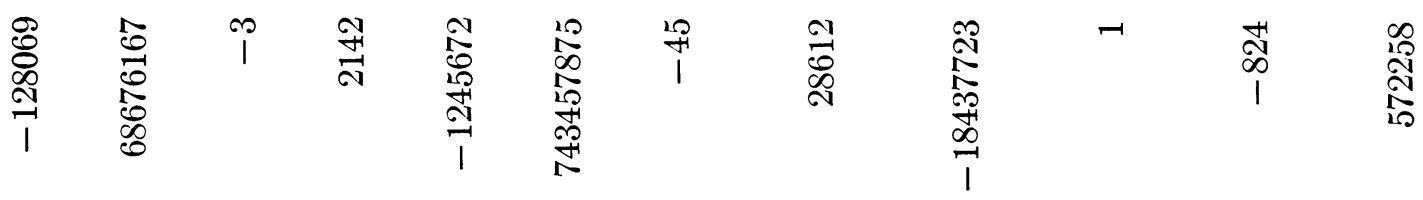

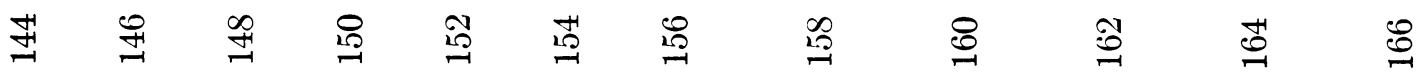




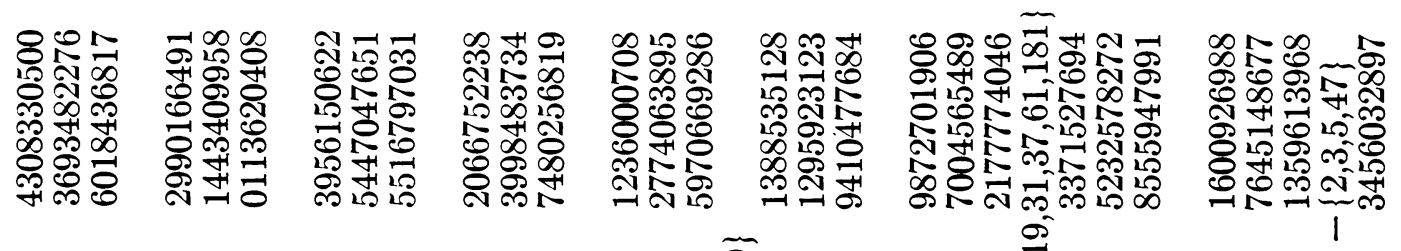

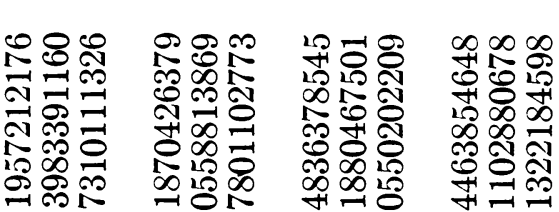

\section{两}

m

†ำ

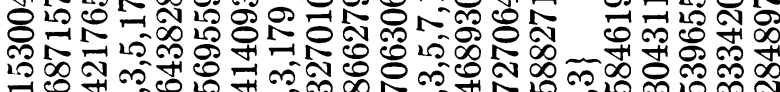
눙

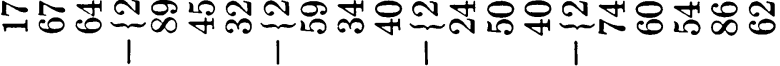

\section{윙오 露 น D.

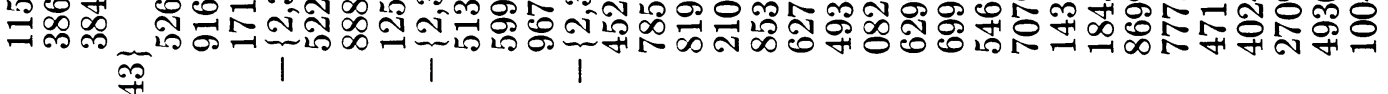
จุ

આ 七.

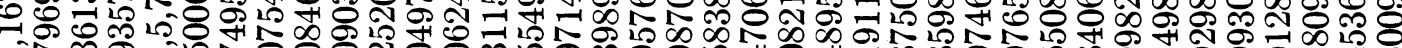

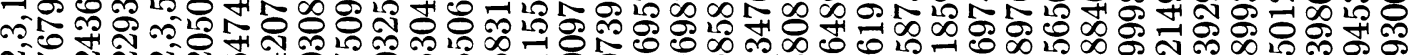

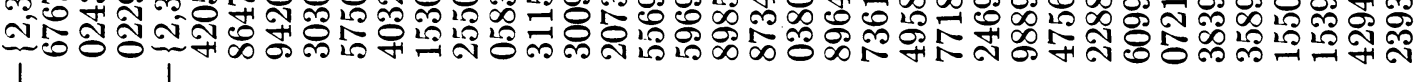

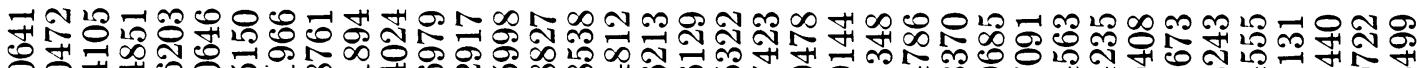

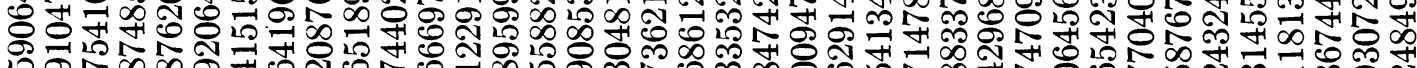
1.

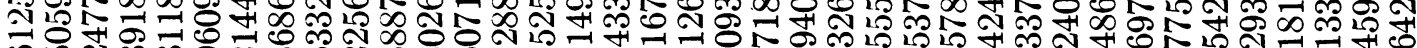

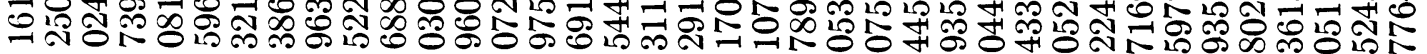

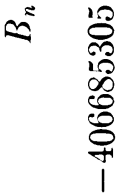
ถุ

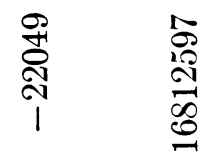
$\stackrel{\wp}{0}$

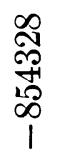

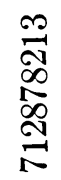
$\stackrel{8}{1}$
\&్
$\approx$
$\stackrel{\infty}{\varrho}$
으
$\stackrel{N}{N}$
亲
$\stackrel{0}{1}$
$\stackrel{\infty}{N}$
$\stackrel{\infty}{\infty}$
$\stackrel{\infty}{\infty}$
Ð
$\infty$ 


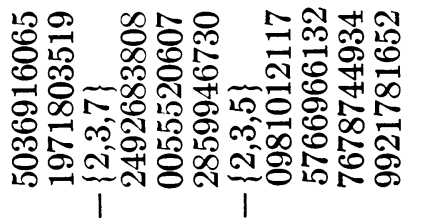

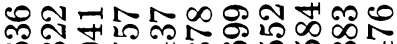
ติ $\infty$ \% 开 品 ฟै

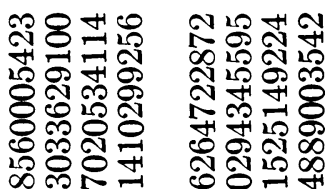

Nofi ॠ

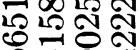
ติ हर

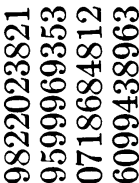

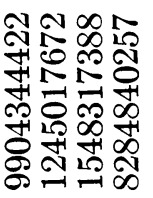

๙ิ सं พิN क N กิ๊

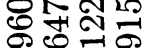
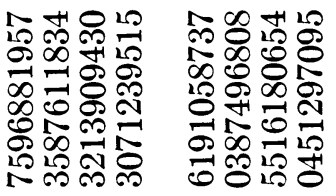

น

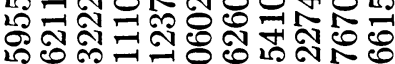
బ. め)

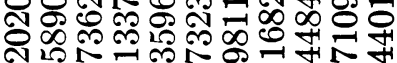

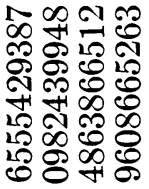

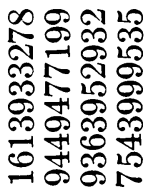

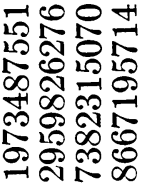

N N พิ ๑ m

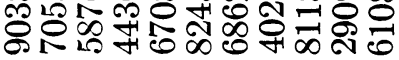

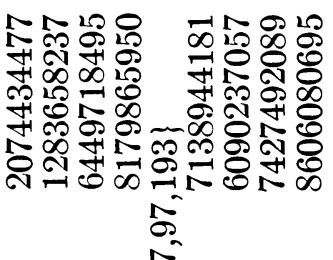
ॠळ กิ N मु

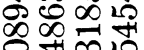

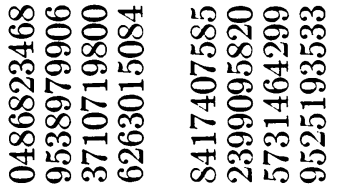

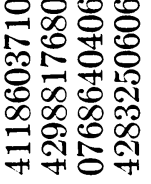

응 낭 $\infty \infty \infty ⿻$ स

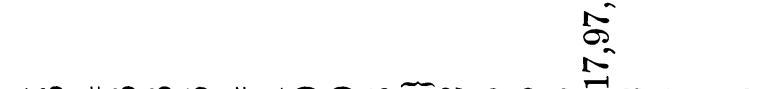

ำ ㄴํ요 $\infty \pi N$ $\infty$ 厄

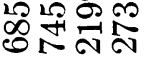

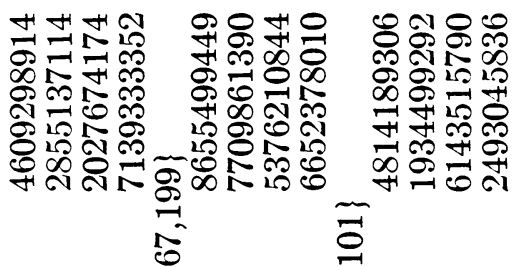
బิ

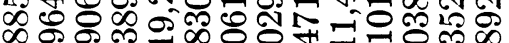
क 0 \% กิ No 0 \%

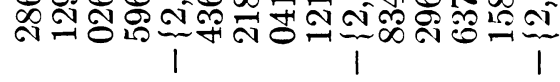

б펵 잉 类

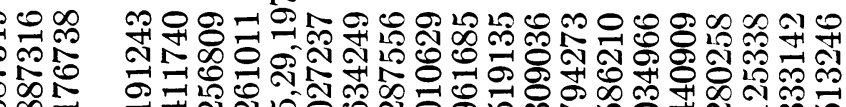

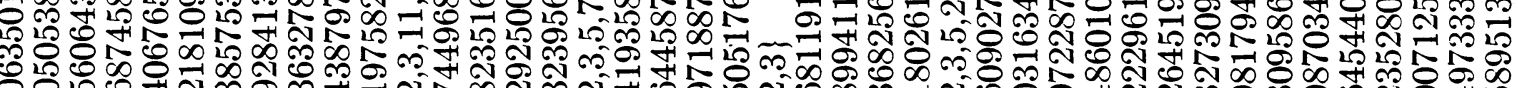
ర

\begin{tabular}{|c|c|c|c|c|c|}
\hline 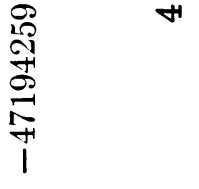 & 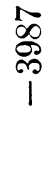 & $\frac{\infty}{\infty}$ & 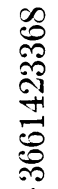 & $\vec{\infty}$ & $\sum_{\substack{+1 \\
\text { N } \\
1}}^{N}$ \\
\hline
\end{tabular}

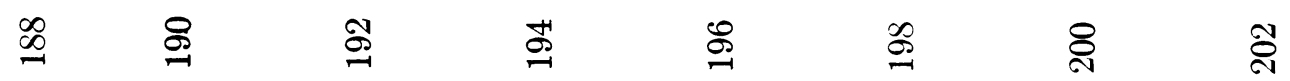




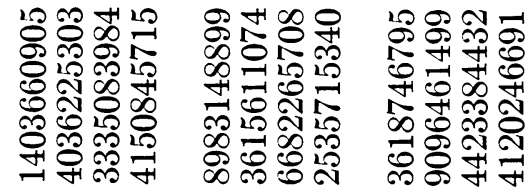
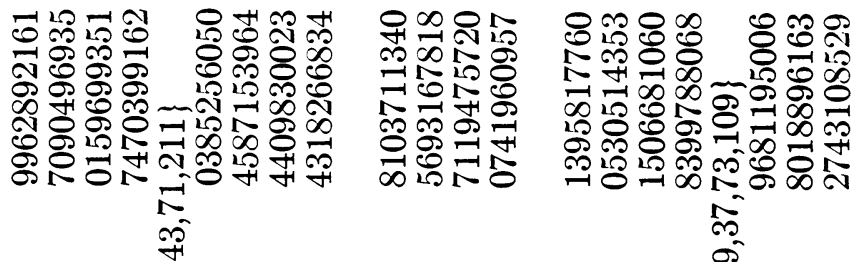

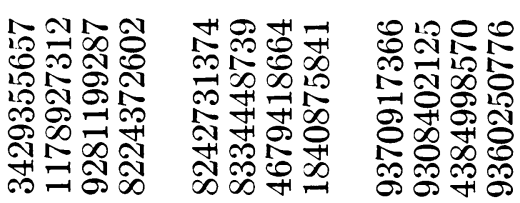

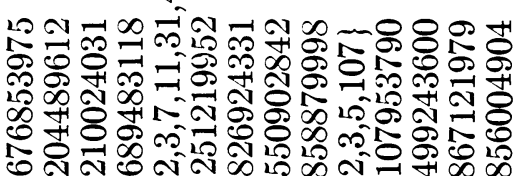

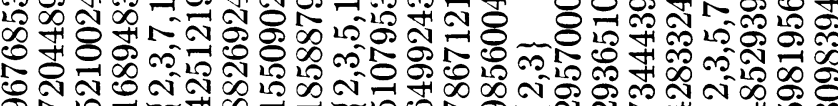
(1)

\section{$\tilde{0}$}

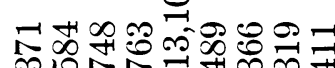
थ.

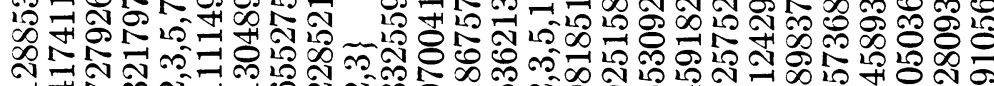

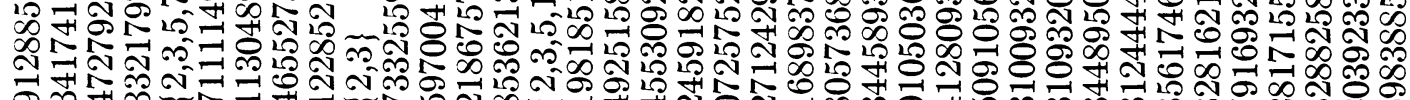

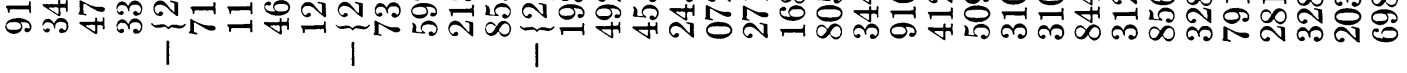

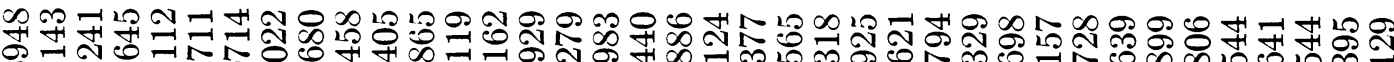

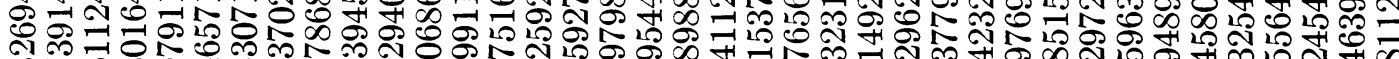


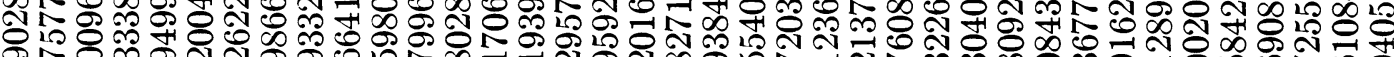

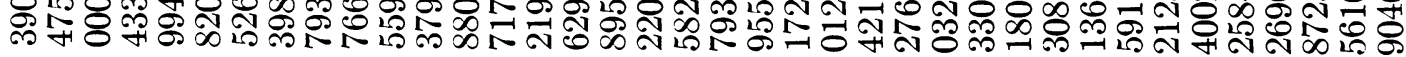

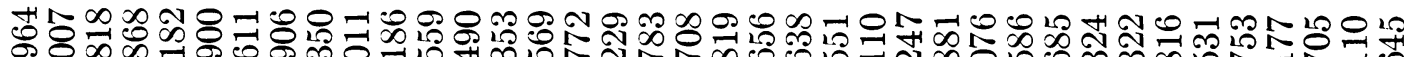
슈 1. 0.4 m

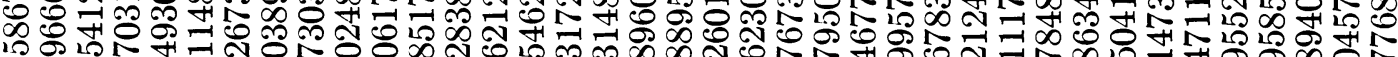

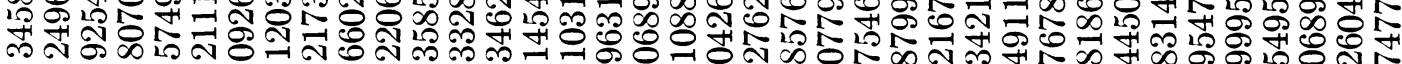
م

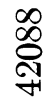

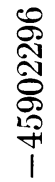
20
$\overbrace{\substack{1 \\ \text { in }}}^{1}$

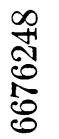

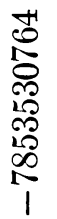
$\vec{F}$
¿
ஓి
๙ิ
$\frac{0}{N}$
$\frac{N}{\mathrm{~N}}$
离
$\stackrel{0}{ה}$
$\stackrel{\infty}{\cdots}$ 


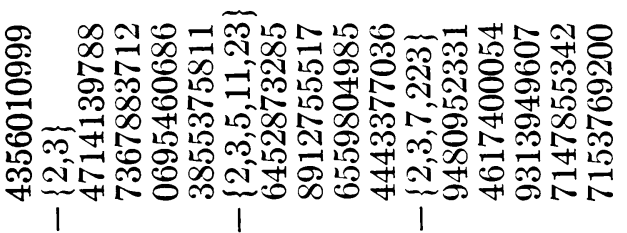

๓ి ๒ Ұ N N.N

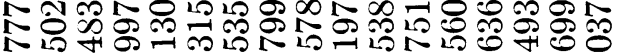

Ұ Nㅠㅇㅛ

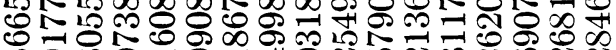
10 年

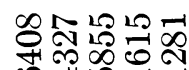
लिए लूखि ऽ N n.

ตัก कN木出

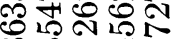
ले 너워요 대

눈영요 क ठ

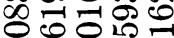
$1 \infty 00 \%$ 斗娄苍苍 रू लि
다요욤요 $\infty$ में $\infty$ iم อ 요요 N
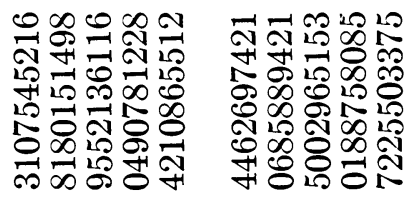

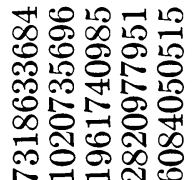

No ผิ กิ กิ
으메요

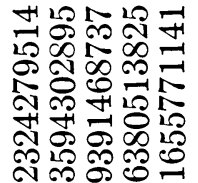

ติ

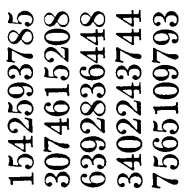

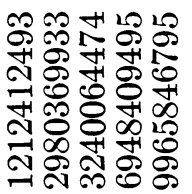

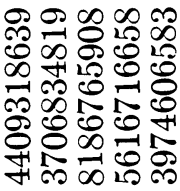

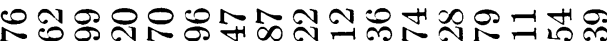

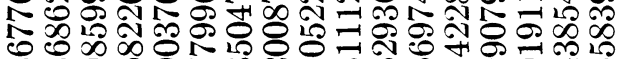
\% \% 征

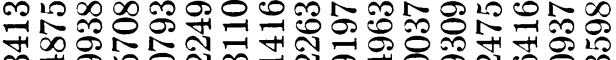

赵舟令 NT $\%$ ले

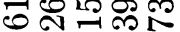
0

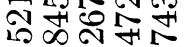

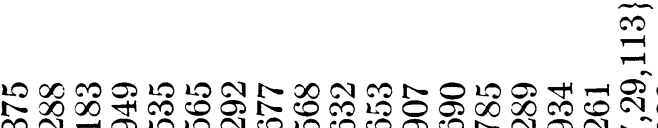

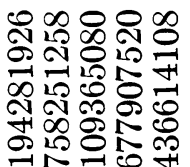

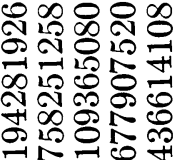

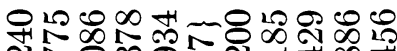

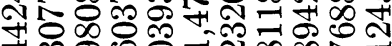

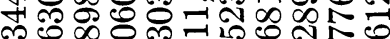
ก.

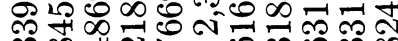
लक त त N

\section{$\widetilde{乛}$}

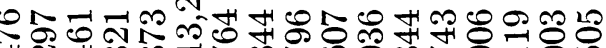

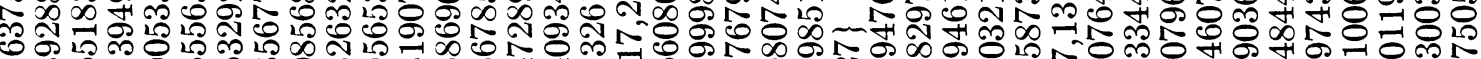

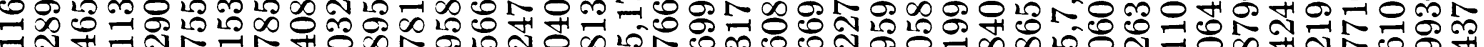

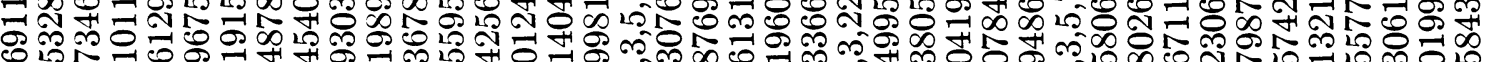

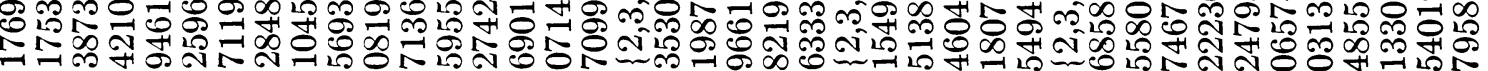
।

$$
\text { I }
$$

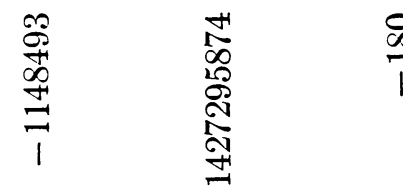

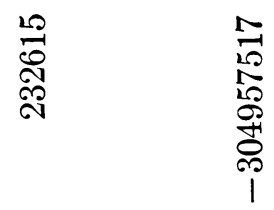

아

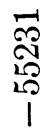

๙ิ

ลิ

ন

สิ

ลั

ศึ

สิ 


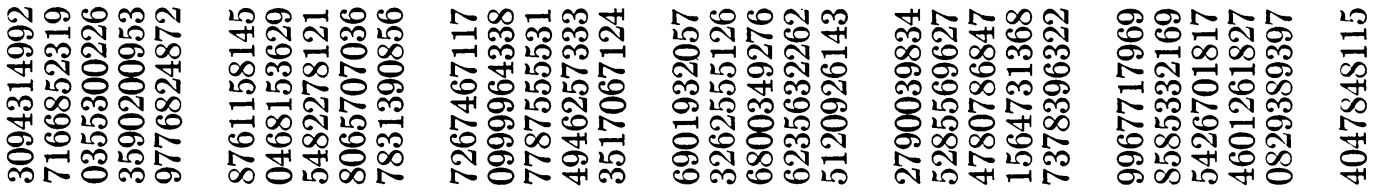

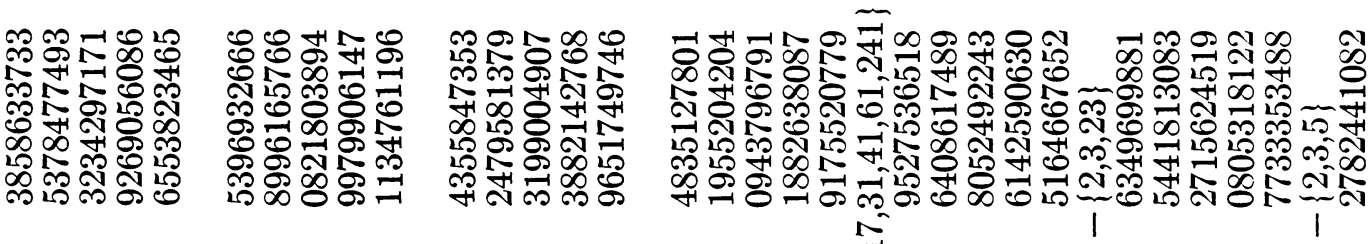

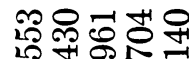
ऽम लू సิ డ 母

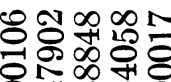
ले

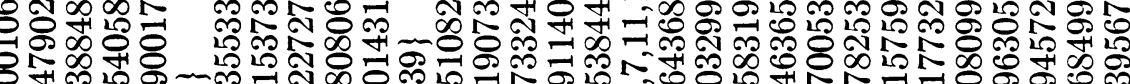

ஸิ

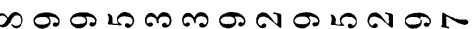
Ұ 그ำ ๓⿴囗十

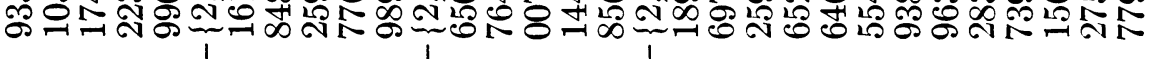

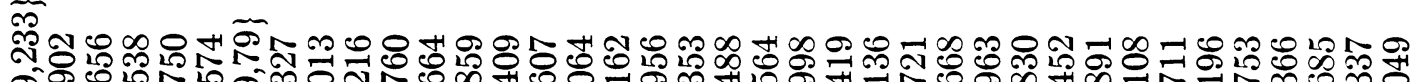
गூ0 బ.

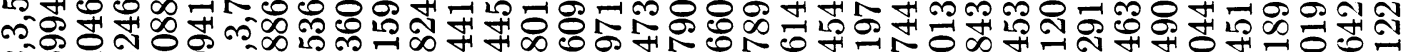

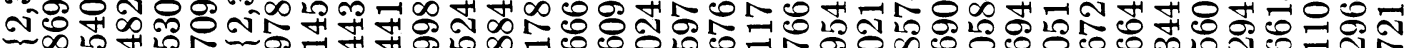
I

भ

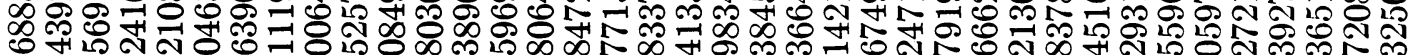
๒

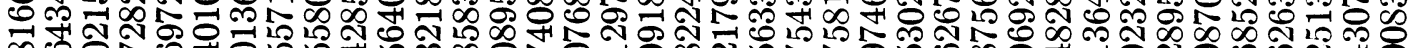

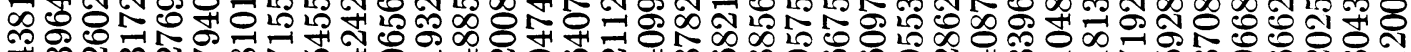
Ұ m

คี กิ

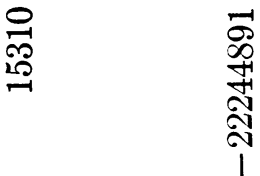

$\infty$

ֻู

No

\&

ััง

ผิ

ஸั

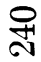

虫

岁

点 

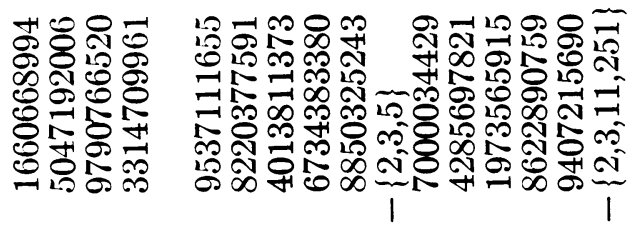

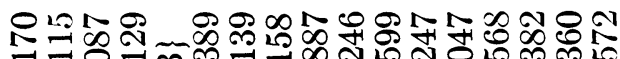
구유요

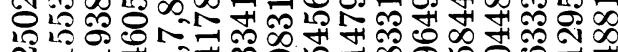
Nష

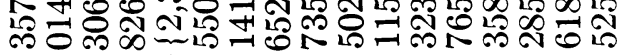
1

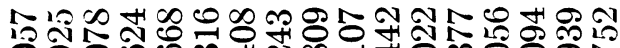

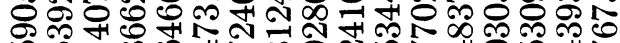

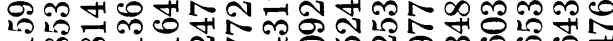
二

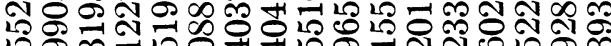

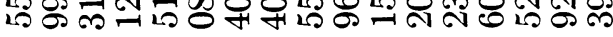

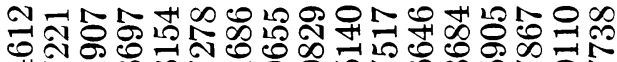
UN

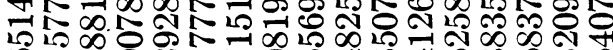

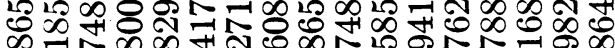
品露

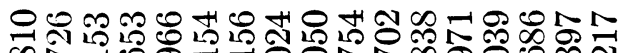

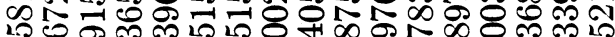
๓.

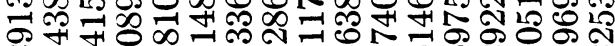
건 రీ 
Mathematics Department

California Institute of Technology

Pasadena, California 91109

1. Thomas Clausen, "Theorem," Astr. Nachrichten, v. 17, 1840, cols. 351-352.

2. S. A. Jofre, "Calculation of the first thirty-two Eulerian numbers from central differences of zero," Quart. J. Math., v. 47, 1916, pp. 103-126.

3. S. A. Joffe, "Calculation of eighteen more, fifty in all, Eulerian numbers from central differences of zero," Quart. J. Math., v. 48, 1917-1920, pp. 193-271.

4. D. H. Lehmer, "An extension of the table of Bernoulli numbers," Duke Math. J., v. 2, 1936, pp. 460-464.

5. Niels Nielsen, Traité Élémentaire des Nombres de Bernoulli, Paris, 1923.

6. J. Peters \& J. Stein, Zehnstellige Logarithmentafel, Berlin, 1922.

7. S. Z. Serebrennikoff, "Tables des premiers quatre vingt dix nombres de Bernoulli," Mém. Acad. St. Petersbourg 8, v. 16, 1905, no. 10, pp. 1-8.

8. K. G. C. von STAUDT, "Beweis eines Lehrsatzes die Bernoullischen Zahlen betreffend," J. für Math., v. 21, 1840, pp. 372-374. 